\title{
La situación socio laboral de la población inmigrante, el caso de Alcalá de Henares*
}

\author{
López Pino, Carmen Marina** \\ ** Socióloga y economista, doctora en sociología por la Universidad Complutense de \\ Madrid. \\ E-mail: carmen982000@yahoo.com
}

\section{Resumen}

Hoy en día España se ha convertido en el principal lugar de emigración de los latinoamericanos, hasta el punto de ser actualmente este colectivo el más importante en dicho país. El presente artículo ilustra a través del estudio de caso de la ciudad de Alcalá de Henares la situación laboral de la población inmigrante en España. Para ello se pregunta cuáles son los determinantes de dicha situación, además de abordar algunos aspectos de las condiciones de trabajo en que se encuentra este colectivo. Teóricamente parte de considerar la existencia de una estructura de desigualdad de oportunidades que lleva a que las trayectorias laborales de los inmigrantes discurran por determinados segmentos del mercado de trabajo.

Palabras clave: Nivel educativo, inmigrantes, mercado de trabajo, situación laboral.

\section{The Social-Labor Situation of the I mmigrant Population, the Alcala de Henares Case}

\begin{abstract}
Recently, Spain has become the principal place for migration among Latin Americans, to the point that presently the Latin American presence in Spain is the highest. This article illustrates throuh a case study in the Alcala de Henares city, the labor situation of the immigrant population in Spain. To reach this objective, the determing factors behind this process need to be established, as well as certain aspects of the work conditions offered in this city. Theoretically the study supposes the existence of a structure of inequalities of opportunity which leads to the fact that labor opportunities for immigrants are limited to certain segments of the labor market.
\end{abstract}

Key words: Educational level, immigrants, employment market, labor situation. 
Recibido: 04-01-17. Aceptado: 04-04-12

\section{I ntroducción}

El crecimiento acelerado de la inmigración en España se da en un contexto de globalización, según el cual el mundo actual sería una enorme y complicada red, en la que todo estaría (y podría llegar a estar) conectado con todo, en un plano de creciente igualdad. Sin embargo, la forma como avanza este proceso apunta a lo contrario: a una mayor jerarquización (Norte/Sur), a un mayor control (por parte de organismos como la OMC, el FMI o el BM) y a una concentración del poder militar (Estados Unidos, como única potencia) (Colectivo IOÉ, 2003: 15). En este contexto, circulan libremente el capital financiero y las mercancías procedentes de los países desarrollados mientras se coloca enormes barreras al libre desplazamiento de las personas procedentes del llamado Tercer Mundo.

Mientras los países desarrollados forman pactos regionales de integración y de libre circulación entre sus "ciudadanos", los países del Tercer mundo, debido a su estructural crisis económica y política, presionan a sus ciudadanos a deambular por los resquicios del primer mundo en busca de un lugar que les permita contar con existencia social, es decir, que les permita integrarse al mercado, base fundamental para la existencia social en el mundo actual.

Huyen no sólo aquellos que siempre han estado bordeando la exclusión social sino las clases medias que observan cómo sus expectativas de integrarse al mercado laboral se desvanecen, y anida en ellos la falta de confianza en sus instituciones y la ausencia de proyectos colectivos que apunten a la reconstrucción de sus sociedades. Huyen hombres y mujeres, llevando consigo no sólo proyectos individuales sino familiares, comunitarios; huyen en busca de un lugar en la sociedad globalizada.

Pero las migraciones no ocurren como un libre fluir de elementos del mundo globalizado, sino como complicados procesos situados en una estructura de oportunidades desiguales. En la actualidad el fantasma de la inmigración recorre los países europeos y deja tras de sí una estela de temor y un clamor por la "seguridad" en una buena parte de los ciudadanos europeos. En un contexto de crisis económica, de cuestionamiento del Estado de Bienestar, es decir, de triunfo de políticas neoliberales, es fácil construir a nivel de lo político y lo social la inmigración como un "problema social" que apunta a la ruptura de sus sociedades. 
Socialmente se construye al inmigrante como un individuo con déficit, como un competidor no legítimo tanto en el mercado de trabajo como en el campo de las oportunidades sociales y de bienestar. Poco a poco va ganando espacio la construcción de una sociedad más encerrada en sí misma, más temerosa, que apuesta a la seguridad por la seguridad y no a la solidaridad, base para repensar una nueva sociedad y dar paso a la política, es decir, al replanteamiento de los fines de la sociedad misma.

Este artículo, pretende desentrañar cuál es la situación de la población inmigrante en España y para ilustrar dicho fenómeno se apoya en un estudio de caso realizado en la ciudad de Alcalá de Henares, segundo municipio de la Comunidad de Madrid con mayor tasa de inmigrantes, alrededor del $12 \%$ de la población total (Padrón Municipal, 2003). Como consecuencia de los cambios políticos y socioeconómicos producidos en las dos últimas décadas, España ha dejado de ser un país de emigración y ha pasado a ser un polo de atracción de los movimientos migratorios, aumentando considerablemente el número de extranjeros que acoge. Aunque no existen datos fiables sobre el número de inmigrantes existentes en el país, lo único cierto es su crecimiento constante en los últimos años, aunque posiblemente menor de la percepción distorsionada propagada por los medios de comunicación. Según el Censo de 1991, la población inmigrante representaba el 0,9\% de la población total, para el 2001 este porcentaje ascendía al 3,8\% (INE, Censo 2001). Es decir, se ha presentado un crecimiento del colectivo de inmigrantes del orden del 350\%, al pasar de 354.000 a 1.573 .000 personas aproximadamente. Posiblemente esta cifra siga creciendo pues el número de residentes no regularizados asciende diariamente sin que tengan una visibilidad estadística.

Alcalá de Henares se ha convertido en la segunda ciudad más receptor de inmigrantes en la Comunidad de Madrid, después de la capital. Según el Padrón Municipal a finales del 2002, los inmigrantes provenientes de Europa del Este eran el grupo más importante, representaban el $53 \%$ del total del colectivo de inmigrantes, le seguían los hispanoamericanos con el 28\%, los africanos con el 12\%, los de Europa Occidental, USA y Canadá con el $5 \%$, mientras los asiáticos eran el grupo más minoritario, el 2\% (Padrón Municipal, noviembre 2002).

Si lanzamos una mirada no por continentes sino por países, observamos cómo la gran mayoría de los inmigrantes procedían de unas pocas nacionalidades. El 30\% eran rumanos, el $10 \%$ colombianos, el $9 \%$ polacos, el $7 \%$ búlgaros, el $6 \%$ ecuatorianos, al igual que los ucranianos, el 4\% marroquíes y el 2\% argentinos (Padrón Municipal Alcalá de Henares, 2002). Es de destacar, que en lo recorrido de este siglo, los colectivos de 
colombianos y argentinos son los que presentan un mayor crecimiento en la ciudad, en términos relativos. Además, la gran mayoría de dichos colectivos suponen la primera generación de inmigrantes en Alcalá. Es de suponer la existencia aún de un frágil tejido asociativo que les impide contar con un importante poder social de negociación dentro de la sociedad alcalaína.

Según el Padrón Municipal, al igual que en España, no se observan grandes diferencias entre la población inmigrante en cuanto a género. En la actualidad, migran tanto hombres como mujeres. Las mujeres ya no son actoras pasivas que siguen al hombre en su proyecto migratorio, ellas elaboran estrategias en el marco de proyectos familiares y o comunitarios, que suelen rebasar sus proyectos individuales. Las brechas por género se acortan cada vez más, incluso, entre los inmigrantes procedentes de países islámicos (caso Marruecos). El 53\% de la población inmigrante son hombres, presentándose leves diferencias entre continentes. Los grupos más masculinos proceden de África y de Europa del Este con $58 \%$ y $56 \%$, respectivamente. Mientras en la colonia hispanoamericana tiene un mayor peso la inmigración femenina: representan el $54 \%$.

La población inmigrante es una población joven. El 17\% tiene menos de 16 a ños, el 80\% está entre los 17 y 56 años, sólo el 3\% supera los 56 años. Si bien es cierto que el grupo de menos edad muestra una tendencia al crecimiento, pues esta población posee mayores tasas de natalidad respecto a la española, también es cierto que a corto plazo representa fundamentalmente un colectivo oferente de mano de obra joven.

¿Son los inmigrantes individuos con déficit? Es decir, individuos sin cualificaciones ni experiencias laborales como suele considerar socialmente un importante grupo de ciudadanos españoles? ¿Son sus déficit los causantes de su ubicación en los segmentos de mercados de trabajo más precarios? O ¿es la estructuración social de los mercados de trabajo y la estructura de desigualdad de oportunidades lo que determina su ubicación? ¿A nivel del colectivo de inmigrantes se preproducen las desigualdades socialmente construidas en términos de género? ¿Qué papel juega las instituciones políticas en la estructuración del mercado de trabajo y en las trayectorias de este colectivo? Reflexionando en torno a estas inquietudes se desarrolla el presente artículo.

\section{Las trayectorias laborales de los inmigrantes en un contexto de exclusión social y de mercados segmentados de trabajo}

El proceso de asentamiento de los inmigrantes pasa por un momento histórico en que las restricciones de sus derechos son la piedra angular de su relación con la sociedad de 
acogida. Superada la clausura territorial y con el déficit situacional que supone el ser no ciudadano, los inmigrantes se enfrentan en una primera etapa de su trayectoria laboral a una situación de precariedad e indefensión laboral y social.

Este déficit situacional de orden estructural cristaliza en su exclusión: laboral, social, cultural y política. Según Weber, en la base de la exclusión social estarían determinados atributos de grupo, raza, lengua, origen, descendencia, que pueden ser tomados para la monopolización de ciertas oportunidades, generalmente económicas, de las que se excluirá de su participación a aquellos que muestren algunas de las características que se señalen. Los excluidos, inferiores y no elegibles, serán considerados competidores no legítimos (o como una amenaza) (Merino, 2001: XXIII).

La exclusión social suele construirse socialmente sobre la base de las diferencias, es decir, de una diferencia (género, procedencia, raza, etnia, clase social, ...) se construye una desigualdad social que se traduce por ejemplo, en el dominio de los hombres sobre las mujeres; en el cierre de oportunidades para los inmigrantes, entre otras. Los conceptos de exclusión social junto con el de mercados segmentados de trabajo y trayectorias laborales permiten analizar la situación laboral del colectivo de inmigrantes de Alcalá de Henares, caso que ilustra la situación de los inmigrantes en buena parte del territorio Español.

La situación laboral de la población inmigrante depende de su ubicación en una estructura social de desigualdad de oportunidades que le lleva a ser revestido de una serie de déficit de orden situacional. En este marco de reflexión, el estudio partió de considerar teóricamente cuatro determinantes de la situación laboral de los inmigrantes: 1) el género, 2) el nivel de cualificación , 3) estar o no regularizado y 4) las redes sociales.

La discusión reciente sobre la segmentación en el mercado de trabajo ha hecho aportes importantes al análisis de la diferenciación social no sólo de la clase asalariada en general sino del colectivo de inmigrantes en particular, entendido el mercado de trabajo como el lugar donde se produce la asignación de probabilidades sociales diferenciales (Dombois, 1997: 447). Esta discusión parte de considerar que las estructuras de desigualdad en los mercados de trabajo no pueden ser explicadas por las "fuerzas del mercado", es decir, por la simple relación entre precios y cantidades. "Existen instituciones y normas que rigen las oportunidades en el mercado de trabajo; limitan y reglamentan la competencia (y movilidad) al interior de la clase trabajadora y crean "non competing group": grupos que no compiten entre sí. Esta división o "segmentación " se basa en procesos de "cierre social" que excluye a determinadas personas de la participación en la competencia por 
determinados empleos y trabajos (Kreckel, 1983: 144; Haller et al., 1985 y Weber, 1962: 31, citado por Dombois, 1997: 447).

Kerr, uno de los autores pioneros sobre la segmentación del mercado de trabajo, constató la "balcanización del mercado de trabajo", es decir, una división del mercado en sectores o segmentos con "fronteras" entre sí, y con reglas propias de admisión y exclusión. Esto llevó a prestar especial atención a las instituciones e intereses que regulan y norman la "locación" así como la exclusión de trabajadores en el mercado de trabajo, con respecto al nivel de remuneraciones, a la estabilidad y a la movilidad laboral (López, 2002).

Son varias las instituciones reguladoras del mercado de trabajo que permiten trascender la simple relación salario-cantidad de fuerza de trabajo, y que con su hacer o no hacer contribuyen a la cristalización del marco de desigualdad de oportunidades. El Estado surge como una de las instituciones más relevantes en la regulación de las probabilidades de mercado de los trabajadores, bien sea en calidad de empleador o por su capacidad para legislar sobre las condiciones de empleo y de trabajo. El oficio o profesión como cristalización del saber reconocido socialmente, por su potencialidad para excluir de oportunidades de empleo a sus no poseedores y establecer normas de regulación interna. El sistema educativo y los procesos de selección establecidos dentro de él, que determinan la distribución social de las cualificaciones. La empresa, con su entramado de normas, convenciones y costumbres que solidifican oportunidades de ingreso, permanencia y ascenso en su interior. Y, por último, las organizaciones sindicales, que estarían llamadas a constituirse en fuerza reguladora del mercado de trabajo.

Es por ello que las instituciones juegan un papel muy importante en la construcción de la estructura de desigualdad de oportunidades que existe en una sociedad determinada. En el marco de esta estructura y de las estrategias elaboradas por los actores discurren las trayectorias laborales de los trabajadores.

El análisis de trayectorias laborales es un método nuevo, fértil para establecer la "permanencia" de las estructuras de desigualdad en el mercado del trabajo y para conocer las probabilidades que tienen las personas de cambiar su situación a lo largo de su vida laboral. La eficacia de las reglas de exclusión, de acceso y permanencia, que caracterizan los mercados de trabajo segmentados, diferentes en cada caso, restan movilidad social a la población inmigrante que, en primer lugar, por criterios institucionales-legales o posesión de determinados atributos son reducidos a determinados segmentos, y en segundo lugar, porque el mercado laboral, cada vez más flexible y desregularizado, ubica 
a este colectivo de manera preferente en segmentos secundarios, restando eficacia a las estrategias adelantadas por este colectivo de forma individual o a través de las redes sociales de pertenencia.

El análisis de trayectorias ubica la situación actual en el contexto de condiciones sociales y antecedentes laborales de las personas, enfocando la continuidad y los cambios en la vida laboral. A través de las trayectorias se reconstruye el proceso de asignación de “personas a posiciones sociales como un proceso relacionado con el tiempo de la vida de las personas, pero al mismo tiempo con una determinada perspectiva del tiempo histórico" (Mayer, 1987: 51, citado por Dombois, 1997: 449).

Las situaciones laborales que viven los inmigrantes de Alcalá de Henares indican diferencias profundas en las oportunidades y en el mercado de trabajo, no sólo con respecto a la población española sino en el interior de este colectivo. Esto supone la existencia de un grupo heterogéneo que tiene en principio en común el hecho de no ser español de nacimiento. El supuesto de que los inmigrantes forman una colectividad, un grupo "sui generis", con características sociales comunes, diferentes a las de los españoles, hace abstracción de la diversidad real que existe entre los inmigrantes y las oportunidades de trabajo diferenciales que estos tienen a través del tiempo. Aunque los inmigrantes compartan algunas condiciones estructurales, como la situación de ser inmigrante, la situación asalariada, la subordinación a determinados trabajos y segmentos, estas condiciones permiten partir de un marco general que si bien determina la situación laboral, no permite observar las diferencias entre algunos grupos y los diferentes caminos o trayectorias laborales que este colectivo va recorriendo.

Por lo cual este estudio partió de preguntarse lo siguiente:

1. ¿El nivel de cualificación determina la situación laboral de la población inmigrante? ¿Logran los inmigrantes valorizar sus cualificaciones en el mercado laboral?

2. ¿Se observan diferencias importantes en las trayectorias laborales de hombres y mujeres?

3. ¿El marco institucional-legal reduce las oportunidades de los inmigrantes, permitiendo una situación de partida diferencial entre los mismos, debido a la circunstancia de tener o no regularizada la situación documental?

4. ¿Las redes sociales sitúan a los inmigrantes en determinados segmentos del mercado de trabajo?

\section{Determinantes de la situación laboral de la población inmigrante}




\subsection{Las diferencias de genero y de cualificación como determinantes en las trayectorias laborales de los inmigrantes}

Con miras a establecer los segmentos de mercados ocupados por los inmigrantes e indagar qué explica las diferencias en sus trayectorias, en este apartado se pregunta, primero, ¿Con qué cualificaciones llegan los inmigrantes de Alcalá a España? Segundo, ¿dónde se ubican cuando llegan, es decir, cuál es su primer trabajo? Tercero, si existe movilidad laboral a través del tiempo, para ello se rastrea sobre su actual o último empleo. Cuarto, se indaga cuán determinante es la cualificación en la diferenciación salarial. Todo ello, considerando la variable género como otra de las variables explicativas, pues se parte de considerar teóricamente que las trayectorias laborales de hombres y mujeres siguen diversos caminos, no sólo en cuanto al tipo de ocupación sino en cuanto al reconocimiento social de sus cualificaciones y nivel de remuneración.

\section{- ¿Con qué cualificaciones llegan los inmigrantes?}

Cada vez más en la sociedad del conocimiento, éase "sociedades desarrolladas", se considera como legítimo la estructuración y diferenciación social acorde a los atributos vinculados a la cualificación. Es decir, en mercados transparentes y competitivos la posesión de una determinada cualificación daría paso a mayores o menores oportunidades laborales. ¿Es esto suficiente? ¿La población inmigrante moviliza sus atributos dentro de la misma estructura de oportunidades que la población nativa? ¿Logra el colectivo de inmigrantes cualificados convertir en valores las cualificaciones poseídas?

El estudio consideró como no cualificadas a aquellas personas que carecían de formación profesional 1 y/o universitaria en su país de origen. Como cualificados a los profesionales de oficio, bien por su formación o experiencia profesional, además, aquellos que poseían formación universitaria pero nunca habían trabajado como tales. Y, por último, cualificados universitarios que teniendo formación universitaria la habían ejercido en su país, tal como se muestra en (Gráfico 1 ). 


\section{Gráfico 1 \\ Inmigrantes por nivel de cualificación en su país de origen}

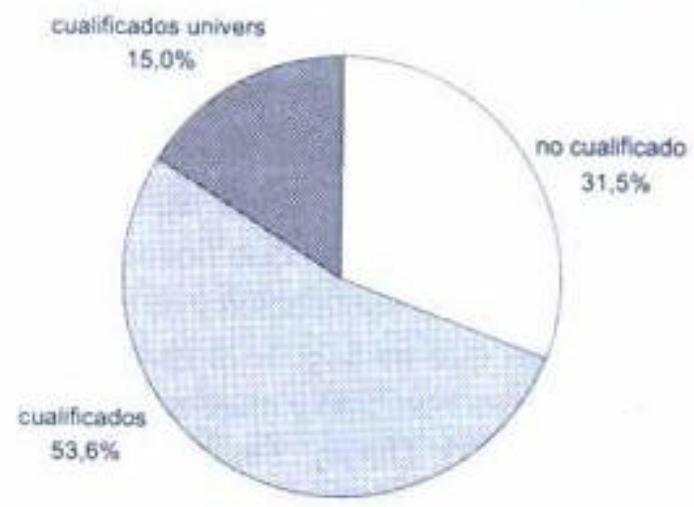

Fuente: Encuesta 2002, Elaboración Propia G540.

A diferencia de lo supuesto a nivel de lo social, la mayor parte de la población inmigrante que ha llegado a Alcalá de Henares tiene pasado laboral y es cualificada. Tiene una edad media de 32 años, el 81\% cuenta con experiencia laboral previa en su país de origen y el $19 \%$ carece de ella. De este último grupo, el 37\% proviene de Europa del Este (rumanos, polacos, búlgaros y ucranianos), el 32\% de África y el $24 \%$ de Latinoamérica. El 53\% tiene alguna cualificación, especialmente profesionales de oficio, y el 15\% son cualificados universitarios, sólo el $32 \%$ se podría considerar "no cualificada" (Gráfico 2).

\section{Gráfico 2}

Nivel de cualificación

por nacionalidad

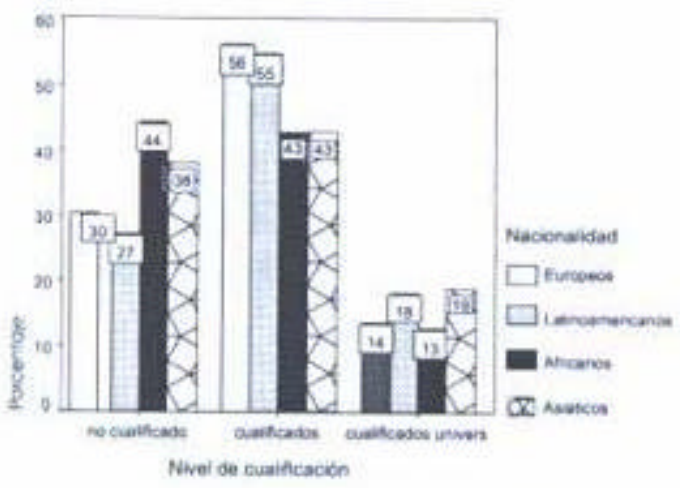

Fuente: encuesta 2002, eiaboración propia G540.

Es de destacar que los de Europa del Este cuentan con una mayor formación técnica o en oficios, y el latinoamericano supera a éste en formación universitaria (sobresalen los argentinos); y el africano presenta la mayor heterogeneidad al ser el único grupo que integra simultáneamente a personas que sólo saben leer y escribir o cuentan con estudios primarios y poseen también estudios universitarios de manera importante (en especial los 
nigerianos).

De lo que se puede llegar a la siguiente conclusión: 1) llegan en edad productiva; 2) con experiencias laborales previas; 3) tienen un importante nivel de cualificación, técnica y universitaria; y 4) estas cualificaciones no están concentradas en ninguna nacionalidad en particular.

\section{- ¿Cuáles son las trayectorias laborales de la población inmigrante por género?}

Cada sociedad delimita los roles asociados a hombres y mujeres no según una diferencia biológica, por sexo, sino en función de género: es decir, la distribución se sostiene sobre construcciones sociales y culturales de las relaciones de sexo. En consecuencia, de una diferencia se construye una desigualdad social que se traduce en el dominio de los hombres sobre las mujeres en la sociedad (Oso, 1998:25). Si bien, en las dos últimas décadas la sociedad Española ha reducido de manera significativa la brecha existente en términos de oportunidades entre hombres y mujeres, aún hoy en día son las mujeres las que poseen mayores tasas de desocupación y de temporalidad, sin que se lleguen a igualar los salarios entre hombres y mujeres (Colectivo IOÉ, 2003; Duran, Serra y Torada, 2001; Oso, 1998). De esta desigualdad de género no son ajenas las mujeres inmigrantes como se demostrará a través del artículo, doble discriminación por su condición de mujer y de inmigrante.

\section{- Las trayectorias laborales de las mujeres inmigrantes}

El $40 \%$ de las mujeres que llegan a España no poseen ninguna cualificación, el $43 \%$ son profesionales cualificadas y el $17 \%$ tiene titulación universitaria. Es de destacar el grupo de tituladas universitarias, que presenta un mayor número que los hombres. El 94\% del total de las mujeres, independientemente de su cualificación, al llegar a España trabajan en labores no cualificadas, sólo el $5 \%$ en cualificadas y el $1 \%$, es decir, dos de ellas en actividades que requieren cualificaciones universitarias (Tabla 1). 
Tabla 1

Mujeres por nivel de cualificación y primera

ocupación en España

\begin{tabular}{|c|c|c|c|c|c|c|c|c|c|c|c|}
\hline & \multicolumn{9}{|c|}{ Primera ocupación por cualificación } & \multicolumn{2}{|c|}{ Total } \\
\hline & \multicolumn{3}{|c|}{ No cualificado } & \multicolumn{3}{|c|}{ Cualificados } & \multicolumn{3}{|c|}{$\begin{array}{l}\text { Cualificados } \\
\text { universitarios }\end{array}$} & \multirow[b]{2}{*}{$\mathrm{N}^{\circ}$} & \multirow[b]{2}{*}{$\%$ col. } \\
\hline & $\mathrm{N}^{\circ}$ & $\%$ fila & $\%$ col. & $\mathrm{N}^{\circ}$ & $\%$ fila & $\%$ col. & $\mathrm{N}^{0}$ & $\%$ fila & $\%$ col. & & \\
\hline No cualificado & 79 & $97,5 \%$ & $41,1 \%$ & 2 & $2,5 \%$ & $20,0 \%$ & & & & 81 & $39,7 \%$ \\
\hline Cualificados & 83 & $94,3 \%$ & $43,2 \%$ & 5 & $5,7 \%$ & $50.0 \%$ & & & & 88 & $43,1 \%$ \\
\hline $\begin{array}{l}\text { Cualificados } \\
\text { universitarios }\end{array}$ & 30 & $85,7 \%$ & $15,6 \%$ & 3 & $8,6 \%$ & $30,0 \%$ & 2 & $5.7 \%$ & $100 \%$ & 35 & $17,2 \%$ \\
\hline Total & 192 & $94,1 \%$ & $100 \%$ & 10 & $4,9 \%$ & $100 \%$ & 2 & $1.0 \%$ & $100 \%$ & 204 & $100 \%$ \\
\hline
\end{tabular}

Fuente: Encueste 2002. Elaboración propia G540.

Si bien sólo el 0,4\% de las mujeres inmigrantes encuestadas habían trabajado en su país en el servicio doméstico, al llegar España el $46 \%$ se ubica en esta ocupación y el $16 \%$ en hostelería. Estos datos confirman la ocupación detectada por otros estudios a nivel de España, que señalan que las mujeres son ubicadas preferentemente en tres sectores: el servicio doméstico, el cuidado de personas ancianas y/o enfermas, y la prostitución. Se trata de sectores en los que, por una u otra razón, se ofrecen condiciones sociolaborales de explotación. Por la forma como se llevó a cabo la recolección de la información, el presente estudio no registró trayectorias laborales en el sector de la prostitución, servicios que pueden ocupar aproximadamente a 300.000 mujeres en España, la gran mayoría de ellas inmigrantes (Solano, 2003: 5).

¿En dónde se encuentra trabajando actualmente la población inmigrante femenina? En la Tabla 2 se perciben leves cambios en las ocupaciones de las mujeres a través del tiempo. Si observamos su última o actual ocupación las mismas continúan trabajando en labores no cualificadas: $93 \%$ frente a un $94 \%$ en su primera ocupación. Incluso, se observa un pequeño aumento en el servicio doméstico al pasar del $46 \%$ al $49 \%$, manteniéndose dicha tendencia en la hostelería. 
Tabla 2

Nivel de cualificación de las mujeres y última o actual ocupación en España

\begin{tabular}{|c|c|c|c|c|c|c|c|c|c|c|c|}
\hline & \multicolumn{9}{|c|}{ Uitima o actual ocupación } & \multirow{2}{*}{\multicolumn{2}{|c|}{ Total }} \\
\hline & \multicolumn{3}{|c|}{ No cualificado } & \multicolumn{3}{|c|}{ Cualificados } & \multicolumn{3}{|c|}{$\begin{array}{c}\text { Cualificados } \\
\text { universitarios }\end{array}$} & & \\
\hline & $\mathrm{N}^{\mathrm{N}}$ & $\%$ fila & $\%$ col & $N^{0}$ & $\%$ fila & $\%$ col & $\mathrm{N}^{2}$ & $\%$ fila & $\%$ col. & $N^{2}$ & $\% \mathrm{col}$. \\
\hline No cualificado & 77 & $95,1 \%$ & $41,0 \%$ & 4 & $4,9 \%$ & $28,6 \%$ & & & & 81 & $39,9 \%$ \\
\hline Cualificados & 81 & $93,1 \%$ & $43,1 \%$ & 6 & $6,9 \%$ & $42,9 \%$ & & & & 87 & $42,9 \%$ \\
\hline $\begin{array}{l}\text { Cualificados } \\
\text { universitarios }\end{array}$ & 30 & $85,7 \%$ & $16,0 \%$ & 4 & $11,4 \%$ & $28,6 \%$ & 1 & $2,9 \%$ & $100 \%$ & 35 & $17,2 \%$ \\
\hline Total & 188 & $92,6 \%$ & $100 \%$ & 14 & $6.9 \%$ & $.100 \%$ & 1 & $.5 \%$ & $100 \%$ & 203 & $100 \%$ \\
\hline
\end{tabular}

Fuente: Enciesta 2002. Elabotación propia G540

Sin embargo, transcurrido un tiempo, aproximadamente cinco años, un grupo muy pequeño de mujeres mejora sus condiciones de trabajo y se ocupa en actividades ligadas al comercio, en calidad de comerciantes y dependientes, ejerce oficios como peluquera y realiza otros trabajos cualificados. Mientras las mujeres con estudios universitarios prácticamente no logran incorporarse al mercado de trabajo en puestos acordes con su formación.

Es de destacar también, que las barreras institucionales existentes para la convalidación de los títulos de los inmigrantes se traduce en cierre de mercados al imposibilitarles la entrada a segmentos de mercados más competitivos y cualificados. Esta barrera institucional es más fuerte para unas titulaciones que otras, es el caso de las áreas ligadas a la salud, al derecho, a la arquitectura, entre otras, pues dichas convalidaciones demandan la realización de estudios en España, situación difícil para el este colectivo por diversas razones: primero, para cursar estudios universitarios el inmigrante debe tener su situación legal regularizada; segundo, debe contar con ingresos y tiempo adicional para compatibilizar estudios con trabajo. Por lo cual la proporción de inmigrantes estudiando y trabajando es poco significativa (2\%).

El no poder abandonar el estado de supervivencia en que se encuentra un importante sector de este colectivo tiene el efecto, dadas estas barreras institucionales y de mercado, de reducir sus trayectorias laborales a segmentos de mercado muy específicos y poco relacionados con su formación o cualificación. Bajo estas circunstancias es difícil que a corto y mediano plazo buena parte de las mujeres inmigrantes puedan ubicarse en sectores diferentes al del servicio domestico y/o domiciliario, pues son servicios con una creciente demanda por parte de la sociedad española. Tres circunstancias favorecen la creciente demanda de esta gama de servicios que se entrelazan entre sí, sin mayor 
regulación ni protección $\underline{2}$ (atención domiciliaria a la tercera edad, servicio doméstico cuidado del hogar, de niños, enfermos y ancianos-), ellas son: 1) El alargamiento de la esperanza de vida de los españoles; 2) el avance en la igualación de oportunidades entre hombres y mujeres que se ha traducido en una mayor escolarización de la mujer y vinculación a la actividad laboral; y 3) El insuficiente desarrollo de los denominados servicios de proximidad (guarderías, asistencia domiciliaria, atención a la juventud, etc.) por parte del Estado (Martín, 2003:8). Servicios que por su baja remuneración y malas condiciones de trabajo suelen ser desestimados por las mujeres y hombres españoles.

\section{- Las trayectorias laborales de los hombres inmigrantes}

El $25 \%$ de los hombres encuestados no poseen ninguna cualificación, el $63 \%$ son profesionales cualificados y el $12 \%$ tiene titulación universitaria. Es decir, el $75 \%$ de ellos posee alguna cualificación. Sin embargo, el 70\% del total de los hombres al llegar a España trabajan en ocupaciones no cualificadas, el $28 \%$ realiza trabajos con cualificación profesional en oficios y el $2 \%$ está trabajando como profesional universitario (Tabla 3 ).

\section{Tabla 3}

Hombres por nivel de cualificación y primera ocupación en España

\begin{tabular}{|c|c|c|c|c|c|c|c|c|c|c|c|}
\hline & \multicolumn{9}{|c|}{ Ultima $o$ actual ocupación } & \multirow{2}{*}{\multicolumn{2}{|c|}{ Total }} \\
\hline & \multicolumn{3}{|c|}{ No cualificado } & \multicolumn{3}{|c|}{ Cualificados } & \multicolumn{3}{|c|}{$\begin{array}{l}\text { Cualificados } \\
\text { universitarios }\end{array}$} & & \\
\hline & $\mathrm{N}^{2}$ & $\%$ fila & $\%$ col & $\mathrm{N}^{2}$ & $\%$ fila & $\%$ col & $\mathrm{N}^{2}$ & $\%$ fila & $\%$ col. & $\mathrm{N}^{2}$ & $\%$ col. \\
\hline No cualificado & 48 & $82,8 \%$ & $27,1 \%$ & 10 & $17,2 \%$ & $14,3 \%$ & & & & 58 & $22,9 \%$ \\
\hline Cualificados & 110 & $67.9 \%$ & $62,1 \%$ & 51 & $31,5 \%$ & $72,9 \%$ & 1 & $6 \%$ & $16,7 \%$ & 162 & $64,0 \%$ \\
\hline $\begin{array}{l}\text { Cualificados } \\
\text { universitarios }\end{array}$ & 19 & $57,6 \%$ & $10,7 \%$ & 9 & $27,3 \%$ & $12,9 \%$ & 5 & $15,2 \%$ & $83,3 \%$ & 33 & $13,0 \%$ \\
\hline Total & 177 & $70,0 \%$ & $100 \%$ & 70 & $27,7 \%$ & $100 \%$ & 6 & $2,4 \%$ & $100 \%$ & 253 & $100 \%$ \\
\hline
\end{tabular}

Fuente: Encuesta 2002. Elaboración propia G540.

A diferencia de las trayectorias laborales de las mujeres, en las de los hombres se observa mayor heterogeneidad y mayor valorización de sus cualificaciones. Si bien, sólo el $14 \%$ de los hombres habían trabajado en su lugar de origen en la construcción, al llegar a España lo hace el $46 \%$, el resto de los inmigrantes lo hace en la hostelería (6\%), en ocupaciones cualificadas $(6 \%)$, como obrero cualificado y no cualificado $(6 \%)$, como dependiente $(2 \%)$, como comerciante $(2 \%)$ y en profesiones universitarias $(2 \%)$.

¿En dónde se encuentra trabajando actualmente la población inmigrante masculina? Las trayectorias laborales masculinas observan mayor dinamismo y movilidad ocupacional comparativamente con las de las mujeres. Se pasa de un $70 \%$ de hombres laborando en 
actividades no cualificadas a un 56\%. Según la Tabla 4, con el transcurrir del tiempo, los inmigrantes cualificados (profesionales de oficio) tienen una mayor probabilidad de lograr un reconocimiento de sus experiencias profesionales. En su actual o última ocupación los inmigrantes con oficio representan el $42 \%$ frente a un $28 \%$ en su primera ocupación; mientras no se observa ningún cambio en las trayectorias laborales de los inmigrantes con formación universitaria $(2,4 \%$ a 2,8\%, ver Tabla 4$)$.

Tabla 4

Nivel de cualificación de los hombres y última o actual ocupación en España

\begin{tabular}{|c|c|c|c|c|c|c|c|c|c|c|c|}
\hline & \multicolumn{9}{|c|}{ Ultima o actual ocupación } & \multicolumn{2}{|c|}{ Total } \\
\hline & \multicolumn{3}{|c|}{ No cualificado } & \multicolumn{3}{|c|}{ Cualificados } & \multicolumn{3}{|c|}{$\begin{array}{l}\text { Cualificados } \\
\text { universitanios }\end{array}$} & \multirow[b]{2}{*}{$\mathrm{N}^{0}$} & \multirow[b]{2}{*}{$\% \mathrm{col}$. } \\
\hline & $\mathrm{N}^{0}$ & $\%$ fila & $\%$ col. & $\mathrm{N}^{\circ}$ & $\%$ fila & $\% \mathrm{col}$ & $\mathrm{N}^{0}$ & $\%$ fila & $\% \mathrm{col}$. & & \\
\hline No cualificado & 41 & $70,7 \%$ & $29,5 \%$ & 17 & $29,3 \%$ & $16,3 \%$ & & & & 58 & $23,2 \%$ \\
\hline Cualificados & 81 & $50,9 \%$ & $58,3 \%$ & 76 & $47.8 \%$ & $73,1 \%$ & 2 & $1,3 \%$ & $28,6 \%$ & 159 & $63,6 \%$ \\
\hline $\begin{array}{l}\text { Cualificados } \\
\text { universitarios }\end{array}$ & 17 & $51,5 \%$ & $12,2 \%$ & 11 & $33,3 \%$ & $10,6 \%$ & 5 & $15.2 \%$ & $71,4 \%$ & 33 & $13,2 \%$ \\
\hline Total & 139 & $55,6 \%$ & $100 \%$ & 104 & $41,6 \%$ & $100 \%$ & 7 & $2,8 \%$ & $100 \%$ & 250 & $100 \%$ \\
\hline
\end{tabular}

Fuente: Encuesta 2002. Elaboración propia G540.

El Tabla 5 muestra cómo los que llegan cualificados en oficios relacionados con la construcción (oficiales, soldadores, pintores, fontaneros, etc.) inmediatamente logran valorizar su formación en el mercado laboral. A su llegada el $43 \%$ se ocupa en labores cualificadas relacionadas con su oficio, y con el paso del tiempo dicho porcentaje llega al $62 \%$. Incluso un $3 \%$ logra ubicarse en otros trabajos cualificados. 
Tabla 5

Nivel de cualificación de los inmigrantes por primera ocupación, última o actual

\begin{tabular}{|c|c|c|}
\hline Cualificación en su pais de origen & $\begin{array}{c}\text { Primera ocupación } \\
\text { en España }\end{array}$ & $\begin{array}{c}\text { Actual o última } \\
\text { ocupación }\end{array}$ \\
\hline \multicolumn{3}{|l|}{ Obreros cualificados } \\
\hline Ubicación en su profesión de origen & $3 \%$ & $23,10 \%$ \\
\hline Ubicación en trabajos cualificados & $21.2 \%$ & $42,30 \%$ \\
\hline \multicolumn{3}{|l|}{ Cualificados en la construcción } \\
\hline Ubicación en su protesión de origen & $43,30 \%$ & $62,10 \%$ \\
\hline Ubicaciòn en trabajos cualificados & $3,30 \%$ & $3,40 \%$ \\
\hline \multicolumn{3}{|l|}{ Conductores } \\
\hline Ubicación en su profesión de origen & $21,10 \%$ & $33,30 \%$ \\
\hline Ubicación en trabajos cualificados & $10,60 \%$ & $20 \%$ \\
\hline \multicolumn{3}{|l|}{ Otros cualificados } \\
\hline Ubicación en su profesión de origen & $5,70 \%$ & $8,20 \%$ \\
\hline Ubicación en trabajos cualificados & $7,90 \%$ & $14,50 \%$ \\
\hline \multicolumn{3}{|l|}{ Profesionales universitarios } \\
\hline Ubicación en su protesión de origen & $8,80 \%$ & $8,80 \%$ \\
\hline Ubicaciön en trabajos cualificados & $15,10 \%$ & $22,10 \%$ \\
\hline
\end{tabular}

En el grupo de cualificados en la industria (mecánicos industriales, matriceros, torneros, fresadores, soldadores, entre otros) sólo el 3\% se ubica en su ocupación en el primer momento de su llegada a España. Transcurrido un tiempo, el 23\% logra ejercer su profesión. Se evidencia una movilidad importante en este grupo, pues con la permanencia en España el 65\% logra ubicarse en trabajos específicos de su profesión y en otros trabajos cualificados. De los encuestados, el grupo de conductores ejerce al llegar su profesión en un $21 \%$ de los casos, y pasado un tiempo se incrementa en un $12 \%$. Más aún, en la actualidad, el $20 \%$ de ellos trabaja en otras ocupaciones cualificadas.

Los anteriores grupos, comparativamente con los no cualificados e incluso con los que tienen formación universitaria, tienen mayores probabilidades de integrarse en el mercado laboral en su respectiva profesión o en otras ocupaciones cualificadas. En una primera instancia, el $9 \%$ de los universitarios logra trabajar en su profesión, lo que hace suponer que especialmente este colectivo cuenta con redes sociales de oficios, ya que este porcentaje se mantiene a lo largo del tiempo.

Los anteriores grupos, comparativamente con los no cualificados e incluso con los que tienen formación universitaria, tienen mayores probabilidades de integrarse en el mercado laboral en su respectiva profesión o en otras ocupaciones cualificadas. En una primera 
instancia, el 9\% de los universitarios logra trabajar en su profesión, lo que hace suponer que especialmente este colectivo cuenta con redes sociales de oficios, ya que este porcentaje se mantiene a lo largo del tiempo.

Por lo anterior, es clara la existencia de segmentos de mercados de trabajo en los que los inmigrantes entran a competir con la mano de obra española, incluso desde un primer momento. Es de destacar que en la década del ochenta en España se presenta una masificación de los estudios superiores universitarios, en desmedro de la formación profesional o técnica, quedando un sector importante de este mercado sin ser atendido. Sólo recientemente dichos estudios vuelven a revalorizarse y a ser considerados por los jóvenes, debido entre otras cosas a las altas tasas de paro de los jóvenes universitarios.

Si se profundiza en el grupo de inmigrantes que llega sin ninguna cualificación representa el $25 \%$ del total de la población masculina- el $83 \%$ desempeña a su llegada trabajos no cualificados y el $17 \%$ lo hace en labores cualificadas. Transcurrido el tiempo, en su última o actual ocupación, el $70 \%$ continua ejerciendo labores no cualificadas, mientras el $29 \%$ desempeña trabajos cualificados especialmente construcción. Es de destacar que se observa una relativa movilidad en sus trayectorias laborales, como consecuencia de su experiencia en España y la confianza dada por sus empleadores $\underline{3}$.

Se puede concluir: 1) es un contingente relativamente cualificado, especialmente en oficios profesionales; 2) se ubican a su llegada preferentemente en segmentos de mercado poco cualificados; 3) con el tiempo un importante grupo accede a segmentos cualificados, acorde a su oficio; y 4) a diferencia de las mujeres sus trayectorias muestran más heterogeneidad y movilidad.

\section{- La cualificación como determinante de la situación laboral de los inmigrantes}

Por último para medir el peso de las cualificaciones en la situación laboral de la población inmigrante, se consideró la relación entre salarios y nivel de cualificación, siendo la variable independiente esta última.

La media salarial de los encuestados no cualificados se sitúa en 490 euros, mientras la de los cualificados en oficios está en 750 euros y la de los profesionales universitarios en 715 euros. Se evidencia el peso que tienen las cualificaciones de oficio, en la situación socio laboral de la población inmigrante, este grupo tiene una media salarial superior en un $53 \%$ a la de los no cualificados (Gráfico 3). 


\section{Gráfico 3 \\ Género y nivel salarial de la población inmigrante}

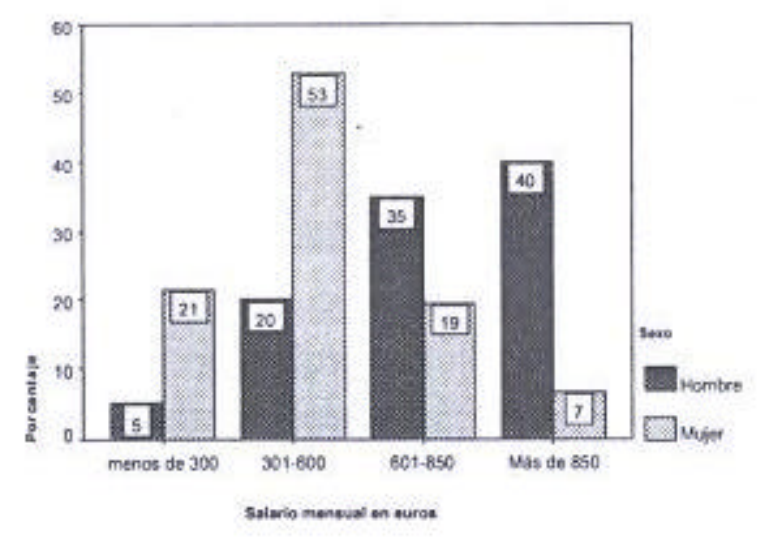

Fuente: Encuesta 2002. Elaboración propia G540.

Pero la distancia mayor a nivel salarial es explicada por el factor género, como lo señala el análisis de las medias. La media salarial de los hombres es de 850 euros y la de las mujeres 425 euros. Es decir, las mujeres ganan un 50\% menos. El análisis estadístico del nivel salarial (variable dependiente) relacionado con la cualificación o el género (variables independientes) arroja niveles de correlación significativa entre dichas variables.

Si bien, cualquiera de los ítem que habitualmente se utilizan para medir la situación laboral de las personas resulta negativo para las mujeres españolas: tienen una menor presencia en el mercado laboral, experimentan mayores niveles de desempleo, están sobre representadas en los empleos temporales y cobran salarios inferiores a los masculinos, esta situación se acrecienta para el caso de las mujeres inmigrantes. Mientras los salarios de las mujeres españolas representan un $68 \%$ del de los hombres (INE, ESIS, primer trimestre, 2003), el de las mujeres inmigrantes representan sólo el $50 \%$ con respecto al de los hombres inmigrantes, como se acaba de señalar. Hay que considerar que por ejemplo, la media salarial a nivel general en el sector de la construcción se encuentra alrededor de 1.200 euros y la de hostelería en 900 euros (Martín, 2003:20), mientras la media de los inmigrantes cualificados se ubica en 750 euros.

Por lo analizado hasta el momento, la cualificación y el género explican de manera significativa la situación diferencial de la población inmigrante, manifestada en trayectorias laborales muy distintas, en el reconocimiento de sus cualificaciones y en la retribución salarial, al interior de este colectivo. 


\subsection{El peso del marco institucional-legal en las trayectorias laborales de la población inmigrante}

“Uno aquí se siente discriminado cuando no tiene papeles, así sea colombiano, sea peruano, ..."

El marco institucional-legal configura otra de las bases de desigualdad de oportunidades entre la población inmigrante y la local. Tradicionalmente a través de su legislación el Estado ha asignado determinados segmentos de mercado laboral al contingente inmigrante, apoyado en la tesis de "no competitividad de la población inmigrante con la nativa". Es decir, los inmigrantes integrarían mercados de trabajo que la población nativa no deseara ocupar o no contara con las cualificaciones requeridas en dicho segmento de mercado. Segmentos caracterizados por su poca cualificación, con cargas físicas importantes, poco remunerados y de escaso reconocimiento social. En los últimos años, sólo aquellos "residentes por arraigo" (que han demostrado que llevan un determinado número de años en España) y aquellos que lleven más de un año como residentes regularizados- podrían entrar a competir en el mercado en "igualdad de condiciones" con la población nativa. El marco institucional configura, en principio, el cierre de oportunidades del mercado, y por tanto la base de la desigualdad de oportunidades laborales y sociales de la población inmigrante. Es así como hasta hace unos años existían cupos de trabajo tanto para mujeres como para hombres. Para las primeras se les reservaba trabajos tales como: servicio doméstico y hostelería; y para los hombres: agricultura y construcción, preferiblemente. En la actualidad, aunque los cupos formalmente establecidos son mínimos, los inmigrantes siguen haciendo parte de dichos segmentos, como veremos a continuación.

Las políticas de la Unión Europea y con ellas las de España apuntan al recrudecimiento del control de los flujos migratorios y a la pérdida de derechos de los inmigrantes no regularizados. La Ley Orgánica 8/2000 representa un retroceso respecto a la Ley Orgánica 4/2000, restringe los derechos fundamentales de los extranjeros y ahonda en la diferenciación entre españoles por un lado y extranjeros por otro y, dentro de éstos últimos, entre extranjeros de primera y extranjeros de segunda en función de su situación documental en el país, afectando gravemente el ejercicio de derechos básicos de todo ser humano, reconocidos por tratados e instrumentos internacionales (manifestación, reunión, asociación, huelga, sindicación, entre otros) en los cuales es parte el Estado español (Moreno, 2003:3). Además, restringe la posibilidad de que el "contingente"ㅆ sea una vía para la regularización de los trabajadores que se encuentran ya en España en una situación irregular, pues se dirige a trabajadores que no se hallen ni residan en el 
territorio español. De hecho, no se vislumbra a corto plazo la regularización del colectivo existente, más aún, con la nueva reforma en trámite parlamentario, el visado pasa a convertirse en la piedra angular de la regulación de extranjería. Con ello se pretende que todos los trámites se realicen en el país de origen y nunca en España, al objeto de desincentivar la entrada irregular de inmigrantes. En los diversos países es bien conocido como las embajadas elevan los requisitos para otorgar el visado, siendo casi imposible emigrar para trabajar con la documentación en regla, e, incluso, es difícil para aquellos que teniendo los medios económicos aspiran a visitar el país en calidad de turistas.

El estudio consideró el hecho de tener o no regularizada la situación legal como uno de los determinantes más importantes para la integración social y laboral de la población inmigrante. Como ya se ha señalado, el marco institucional-legal establece las bases para la legalización y, en parte, legitimación de la desigualdad de oportunidades entre la población inmigrante y la nativa. Más aún, el no contemplar la regularización de un importante contingente de inmigrantes reduce a éste a los segmentos más desregularizados, a la economía sumergida, es decir, a la "mercantilización pura" de la fuerza de trabajo, que supone la ausencia o débil presencia de instituciones reguladoras del mercado laboral, con lo cual la fuerza de trabajo queda expuesta a las fluctuaciones del mercado y desprovista de protecciones sociales y políticas (Prieto, 2001:20). Según Martín (2003), la economía sumergida en España puede llegar a representar una cuarta parte del PIB español, situación que atenta contra la estructuración del mercado laboral español, pues es un "agujero negro" en donde los logros laborales alcanzados por los trabajadores españoles se desvanecen. Es en este proceso de "mercantilización pura" donde los inmigrantes quedan atrapados y señalizados como los responsables de bajar las condiciones de trabajo de la población autóctona, sin ser atacada la raíz del problema: la no regularización del colectivo de inmigrantes y la economía sumergida existente.

Con la ampliación de la mercantilización de la fuerza de trabajo no termina la segmentación del mercado laboral, sino que aumentan el segmento poco regulado poseedor de mínimas protecciones sociales- y los sectores que están por fuera del mercado cuyas pericias no son convertibles en valores sociales (López, 2002:163). Es así como los inmigrantes no regularizados ocupan el segmento de mercado más precario y transitan en la sociedad sin mayor reconocimiento social ni derechos. Parafraseando a Auguste Comte sobre los orígenes del proletariado: "acampan en la sociedad sin ubicarse en ella" (citado por Castel, 1997: 325). Esta situación de estar al margen de la sociedad, de no ser ciudadano pleno, de no sentirse igual como persona, es expresada por una inmigrante búlgara que señalaba que su principal preocupación era: 
“Resolver el problema de los papeles, así no tengo que andar escondiéndome. ¡Lo importante son los papeles!".

Con miras a comprobar el peso del marco institucional sobre las trayectorias de los inmigrantes se intentó averiguar, primero, cuántos de los encuestados estaban regularizados; segundo, qué porcentaje de ellos estaba ocupado; y tercero, si se observaban diferencias importantes en términos de remuneración entre los inmigrantes regularizados y los que no lo estaban.

En el presente estudio el $59 \%$ de los encuestados se hallaba regularizado, de los cuales el $58 \%$ eran hombres y el $42 \%$ mujeres (Gráfico 4 ). Es de prever que el contingente no regularizado esté en peor situación que aquellos que lo están, marcando igualmente diferencias de oportunidades el hecho de ser hombre o mujer (Gráfico 5).

\section{Gráfico 4 \\ Género y situación legal de los inmigrantes}

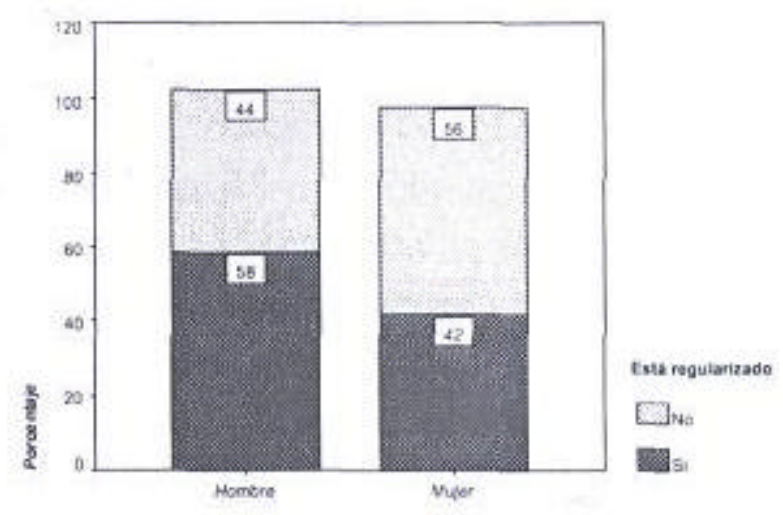

Fuente: Encuesta 2002. Elaboración propia G540. 


\section{Gráfico 5 \\ Situación legal de los \\ desempleados por género}

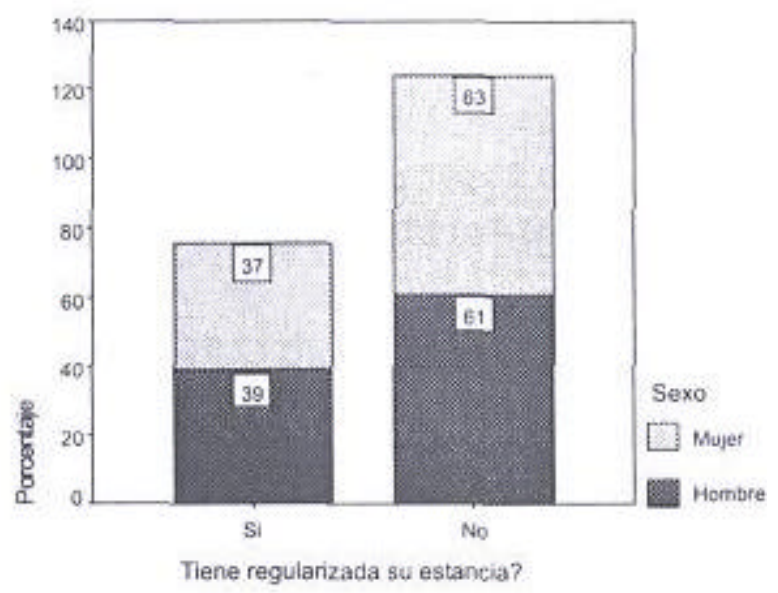

Fuente: Encuesta 2002. Elaboración propia G540.

\section{- ¿En qué situación laboral se encuentran los inmigrantes sin papeles?}

Según las Tablas 6 y 7 el mayor porcentaje de desempleados se encuentra entre los inmigrantes no regularizados. El $57 \%$ de los hombres y el $53 \%$ de las mujeres no regularizados se encontraban sin trabajo en el momento de realizar la encuesta, comparado con el $19 \%$ de los hombres y el $30 \%$ de las mujeres regularizadas. Es de destacar que la tasa de paro o desempleo de la población inmigrante regularizada y no regularizada es superior a la de la población española, situándose en un $36 \%$ frente a un $11,73 \%$ (INE, EPA, primer trimestre 2003). 
Tabla 6

Mujeres por situación laboral y regularización

\begin{tabular}{|c|c|c|c|c|c|c|c|c|}
\hline & \multicolumn{6}{|c|}{ Tiene regularizada su estancia? } & \multicolumn{2}{|c|}{ Total } \\
\hline & \multicolumn{3}{|c|}{ Si } & \multicolumn{3}{|c|}{ No } & \multirow[b]{2}{*}{$\mathrm{N}^{\circ}$} & \multirow[b]{2}{*}{$\% \infty \mathrm{col}$} \\
\hline & $\mathrm{N}^{\mathrm{e}}$ & $\%$ fila & $\% \mathrm{col}$ & $\mathrm{N}^{0}$ & $\%$ fila & $\%$ col. & & \\
\hline $\begin{array}{l}\text { Estudiando y } \\
\text { trabajando }\end{array}$ & 4 & $66,7 \%$ & $3,3 \%$ & 2 & $33,3 \%$ & $1,7 \%$ & 6 & $2,5 \%$ \\
\hline Ocupado & 74 & $58,3 \%$ & $60,7 \%$ & 53 & $41,7 \%$ & $44,2 \%$ & 127 & $52,5 \%$ \\
\hline $\begin{array}{l}\text { Parado } \\
\text { buscando el } \\
\text { primer empleo }\end{array}$ & 9 & $24,3 \%$ & $7,4 \%$ & 28 & $75,7 \%$ & $23,3 \%$ & 37 & $15,3 \%$ \\
\hline $\begin{array}{l}\text { Parado trabajado } \\
\text { antes }\end{array}$ & 28 & $44,4 \%$ & $23,0 \%$ & 35 & $55,6 \%$ & $29,2 \%$ & 63 & $26,0 \%$ \\
\hline Otros & 7 & $77,8 \%$ & $5,7 \%$ & 2 & $22,2 \%$ & $1.7 \%$ & 9 & $3,7 \%$ \\
\hline Total & 122 & $50,4 \%$ & $100 \%$ & 120 & $49,6 \%$ & $100 \%$ & 242 & $100 \%$ \\
\hline
\end{tabular}

Fuente: Encuesta 2002. Elaboración propia G540.

Tabla 7

Hombres por situación laboral y regularización

\begin{tabular}{|c|c|c|c|c|c|c|c|c|}
\hline & \multicolumn{6}{|c|}{ Tiene regularizada su estancia? } & \multicolumn{2}{|c|}{ Total } \\
\hline & \multicolumn{3}{|c|}{ Si } & \multicolumn{3}{|c|}{ No } & \multirow[b]{2}{*}{$\mathrm{N}^{2}$} & \multirow[b]{2}{*}{$\% \mathrm{col}}$. \\
\hline & $\mathrm{N}^{0}$ & $\%$ fila & $\%$ col. & $\mathrm{N}^{2}$ & $\%$ fila & $\%$ col. & & \\
\hline $\begin{array}{l}\text { Estudiando y } \\
\text { trabajando }\end{array}$ & 3 & $60,0 \%$ & $1,7 \%$ & 2 & $40,0 \%$ & $2,2 \%$ & 5 & $1,9 \%$ \\
\hline Ocupado & 139 & $79,0 \%$ & $79,0 \%$ & 37 & $21,0 \%$ & $40,7 \%$ & 176 & $65,9 \%$ \\
\hline $\begin{array}{l}\text { Parado } \\
\text { buscando el } \\
\text { primer empleo }\end{array}$ & 7 & $31,8 \%$ & $4,0 \%$ & 15 & $68,2 \%$ & $16,5 \%$ & 22 & $8,2 \%$ \\
\hline $\begin{array}{l}\text { Parado trabajado } \\
\text { antes }\end{array}$ & 26 & $41,3 \%$ & $14,8 \%$ & 37 & $58,7 \%$ & $40,7 \%$ & 63 & $23,6 \%$ \\
\hline Otros & 1 & $100 \%$ & $.6 \%$ & & & & 1 & $.4 \%$ \\
\hline Total & 176 & $65,9 \%$ & $100 \%$ & 91 & $34,1 \%$ & $100 \%$ & 267 & $100 \%$ \\
\hline
\end{tabular}

Fuente: Encuesta 2002. Elaboración propia G540.

Uno de los puntos de inflexión de las trayectorias laborales de los inmigrantes es el momento de la regularización. Esta amplía los márgenes de libertad y abre las posibilidades a la elaboración de un abanico más amplio estrategias por parte de los inmigrantes. En un grupo de discusión de inmigrantes con papeles se escucharon los siguientes comentarios:

“Con la regularización del 2000, recibo una oferta de trabajo. Cuando estaba sin papeles me pagaban, pero no tenía paga extra, ni vacaciones, ni prestaciones, ni ¡nada! 
[Inmigrante rumano].

- “Cuando usted tiene los papeles es más difícil que lo exploten, porque uno se puede ir a otra parte donde le paguen más"[inmigrante colombiano].

Según la Tabla 7, el 79\% de los hombres regularizados estaban ocupados frente al $41 \%$ de los no regularizados. Situación similar se observa en las mujeres, el $61 \%$ y $44 \%$ respectivamente (Tabla 6). Estos mismos resultados pueden interpretarse en términos individuales. Se puede hablar que es mucho más probable que un hombre regularizado esté ocupado que uno que no lo está ( 38 más probable). Igual para el caso de las mujeres (0,17 más probable).

En sí mismo el hecho de ser mujer supone una menor valorización de su fuerza de trabajo manifestada a través de los salarios, situación que se agrava cuando concurre con la circunstancia de no estar regularizada. El $74 \%$ del total de las mujeres encuestadas ganan menos de 600 euros mensuales y el $21 \%$ menos de 300 euros. Percibiendo el $84 \%$ de aquellas que no poseen los permisos reglamentarios unos ingresos medios mensuales inferiores a 600 euros, mientras que este porcentaje se reduce hasta el $66 \%$ para aquellas que tienen regularizada su situación (Gráfico 6).
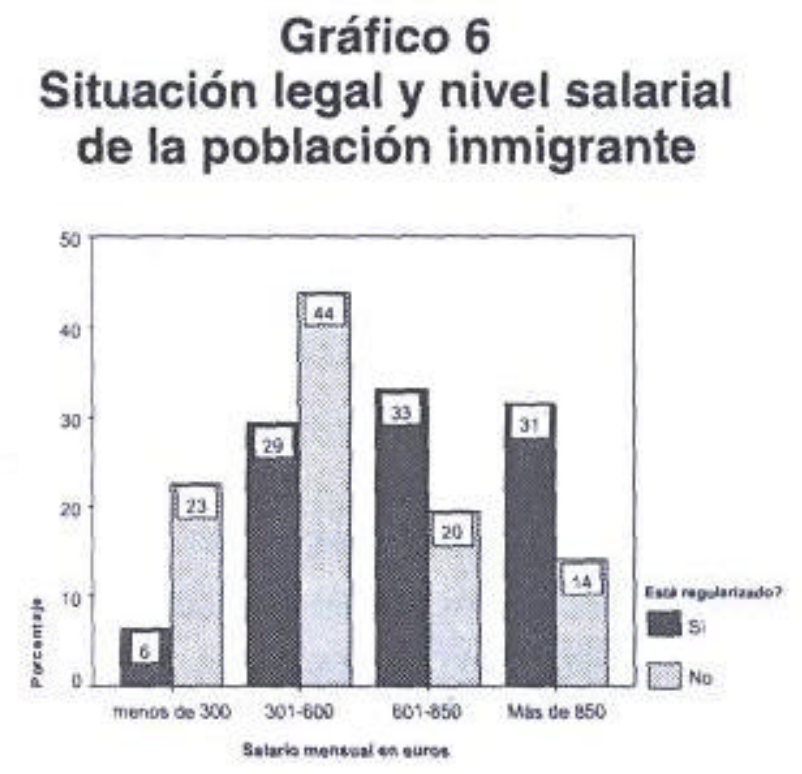

Fuente: Encuesta 2002. Elaboración propia G540.

Al relacionar el nivel salarial con la situación legal de los inmigrantes la media salarial de los no regularizados se sitúa en 450 euros, mientras la población regularizada está en 790 euros. Estas diferencias se ahondan si se compara con el salario medio español: 1.370 euros aproximadamente (INE, ESIS, primer trimestre 2003). 
Como se observa el ámbito legal es uno de los principales determinantes de la situación laboral y condiciones de trabajo de los inmigrantes. Es de aclarar que las distancias saláriales entre regularizados y no regularizados debe ser mayor, pues si bien estos últimos en un momento determinado pueden tener salarios similares a los regularizados incluso, a la población nativa-, en el momento de ser despedidos no cuentan con una serie de ventajas sociales cristalizadas en la figura del "finiquito", de las prestaciones por desempleo y los derechos que se regulan en los convenios colectivos o en el Estatuto de los Trabajadores.

A manera de conclusión ser hombre, en las circunstancias actuales, estar regularizado y tener un oficio, supone tener mayores probabilidades no sólo de ingresar al mercado laboral sino de contar con mejor salario y condiciones de trabajo como lo indica el análisis de las medias (Tabla 8). Cabe destacar que sólo un grupo relativamente importante reúne los anteriores atributos: el $42 \%$ del total de hombres y el $22 \%$ del total de la población inmigrante encuestada.

Tabla 8

Medias salarial general y medias según el determinante género, regularización y cualificación

\begin{tabular}{lccc}
\hline & Media salarial general & Media & $\begin{array}{c}\text { Diferencia respecto } \\
\text { a la media general }\end{array}$ \\
\hline Ser hombre & 710 & 850 & $+20 \%$ \\
Ser Mujer & 425 & $-40 \%$ \\
Estar regularizado & 790 & $+11 \%$ \\
No estar regularizado & 450 & $-37 \%$ \\
Tener cualificación & 750 & $+6 \%$ \\
No tener cualificación & 490 & $-31 \%$ \\
\hline
\end{tabular}

Fuente: Encuesta 2002, Elaboración Propia G540.

En contraste, el grupo con peor situación laboral se encontraría en el de mujeres sin papeles, con o sin cualificación alguna, es decir, el $62 \%$ del total de mujeres $\underline{5}$. Una inmigrante búlgara sin papeles comentaba con un tono amargo:

“Mis amigas ganan el doble que yo, pero no trabajan en una casa, trabajan en tiendas, en una fábrica, si no tienes papeles lo único que puedes hacer es trabajar en una casa ¡Es normal!... bueno, los papeles son importantes..."

Como se evidencia el marco institucional-legal es uno de los principales determinantes 
de la situación laboral de la población inmigrante, pero cabría preguntarse también ¿qué papel tienen las redes sociales en que se desenvuelve este colectivo?

\subsection{Las redes sociales como otro de los determinantes de la situación laboral de la población inmigrante}

No es suficiente disponer de cualidades, conductas y atributos demandados por el mercado laboral como el hecho de ser joven, estar regularizado o poseer una cualificación determinada, es necesario estar vinculado a una red social. ¿Cómo acceden los inmigrantes al trabajo? ¿Qué tipos de segmentos de mercado de trabajo configuran las redes sociales de los inmigrantes? Estos interrogantes son los que inquietan en este apartado, pues se parte de considerar las redes sociales como uno de los determinantes fundamentales de la situación laboral de la población inmigrante. Autores como Massey et al. (1987), plantean cómo la migración, en su proceso inicial, está originada por factores estructurales y externos, pero posteriormente adquiere una dinámica interna propia que se retroalimenta a través del desarrollo de redes sociales. Además, para algunos autores las redes constituyen microestructuras mediadoras que facilitan y perpetúan la migración como un proceso social autosuficiente. Dombois (1997:509) señala: “En un contexto donde las instituciones sociales -como la educación, la formación técnica o los oficiostienen poco impacto en la normalización de los accesos a empleos y de las trayectorias laborales, la red social es un recurso de gran importancia en la definición de las estrategias en el mercado de trabajo y para la estructuración de las trayectorias laborales. La familia, los amigos o vecinos del barrio, los compañeros de trabajo forman la red social que constituye el medio más importante que orienta las estrategias en el mercado laboral".

Si bien el mercado de trabajo español está relativamente institucionalizado, la condición particular del inmigrante aumenta la importancia de las redes sociales para su vinculación al mercado de trabajo. Primero, su llegada supone el aprendizaje de códigos idiomáticos, sociales y laborales, los cuales son construidos, interpretados y reinterpretados a través de la red de familiares, amigos o conocidos. Segundo, su situación de irregularidad legal le lleva a moverse en la economía sumergida o en segmentos de mercado poco regularizados cuyo acceso suele estar mediado por contactos personales, de ahí la importancia de las redes, en especial en una primera etapa. Una mujer inmigrante ucraniana comentaba:

“En general los que vienen son trabajadores, creo que no se tiene en cuenta la nacionalidad para trabajar sino que se tengan recomendaciones, que le hayan hablado 
otras personas, que te recomienden para el trabajo y respondan por ti".

El presente estudio halló que las redes sociales cumplen un papel estratégico desde el comienzo de las trayectorias laborales de los inmigrantes. La gran mayoría de los trabajadores consiguen su primer trabajo por recomendaciones de familiares o amigos (76\%); mientras que los medios anónimos juegan un papel mucho menor (16\%) al igual que los institucionales ( $2 \%)$, sin distingo de género. Aunque con el transcurrir del tiempo de estancia en España se observa una leve disminución del uso de las redes primarias para acceder al actual o último trabajo, éstas continúan cumpliendo un papel estratégico: el $65 \%$ de los inmigrantes recurrieron a ellas (Tabla 9). A la vez que éstas pierden importancia, lo ganan mecanismos más formales o anónimos, como son las ETTs, los periódicos o el Instituto Nacional de Empleo, utilizados especialmente por los inmigrantes regularizados, mientras los no regularizados siguen acudiendo a las redes primarias.

Tabla 9

Forma de acceso al primer, actual o último trabajo

\begin{tabular}{|c|c|c|c|c|}
\hline \multirow{2}{*}{$\begin{array}{c}\text { Mecanismos de acceso } \\
\text { al trabajo }\end{array}$} & \multicolumn{2}{|c|}{ Primer trabajo en España } & \multicolumn{2}{|c|}{ Actual o último trabajo } \\
\hline & $\begin{array}{c}\text { Total } \\
\text { recuento }\end{array}$ & $\%$ & $\begin{array}{c}\text { Total } \\
\text { recuento }\end{array}$ & $\%$ \\
\hline Familia y amigos & 348 & 76,3 & 291 & 65,0 \\
\hline ETT & 11 & 2,4 & 19 & 4,2 \\
\hline INEM & 3 & 0,7 & 6 & 1,3 \\
\hline Periódicos, avisos & 32 & 7,0 & 56 & 12,5 \\
\hline Anunciándose & 27 & 5,9 & 32 & 7,1 \\
\hline ONG & 7 & 1,5 & 43 & 9,6 \\
\hline Otros & 28 & 6,1 & 1 & 0,2 \\
\hline Total & 456 & 100,0 & 448 & 100,0 \\
\hline
\end{tabular}

Fuente: encuesta 2002, elaboración propia G540.

¿Pero qué segmentos de mercado suelen cubrir las redes sociales de los inmigrantes? Como ya se ha demostrado son segmentos de mercado secundario, algunos poco regularizados, con bajos salarios y condiciones de trabajo precarias. Esto permite observar la otra cara de las redes sociales, pues estas no sólo se constituyen como vínculos sociales que apuran el aprendizaje social y laboral de la población inmigrante, sino que contribuyen a cristalizar y estructurar su situación de clase. Situación que se traduce en solidificación de estructuras ocupacionales y de oportunidades de empleo, pues los trabajadores inmigrantes tienden a recorrer caminos similares a los de sus congéneres, amigos y personas cercanas que se encuentran en igual situación de clase. Prieto (1994:133) señala: “Estas redes sociales no se distribuyen de un modo aleatorio; se hallan estratificadas como los recursos económicos y los niveles educativos y forman parte 
de su propia estructura. Las redes sociales actúan sobre las condiciones de empleo a lo largo de toda la vida laboral, pero actúan de un modo especial en el momento de la transici ón inicial al trabajo".

Para este colectivo, especialmente para aquellos no regularizados, las redes sociales no sólo contribuyen a situar socialmente a los inmigrantes, sino que son por antonomasia la institución social básica de solidaridad, pues las estrategias adelantadas por este colectivo dependerán fundamentalmente de sus recursos de poder.

El $58 \%$ de los encuestados conviven con su familia y el $39 \%$ con amigos y familia. Aunque las mujeres tienden levemente a vivir más con la familia ( $61 \%$ frente a $51 \%$ de los hombres), la diferencia importante se observa entre los regularizados y los no regularizados. El $68 \%$ de los regularizados convive con su familia, mientras los no regularizados lo hacen en un $32 \%$. Este último grupo suele habitar fundamentalmente con amigos o con familia y amigos (64\%), y cuenta con condiciones de vivienda más precarias.

Según la encuesta, cuatro de los entrevistados desempleados recibían prestaciones por desempleo, y sólo una persona recibía algún tipo de pensión. El 29\% del total de la muestra recibía otros ingresos, de este grupo el $69 \%$ eran mujeres. Los apoyos económicos provenían fundamentalmente de la familia ( $85 \%$ ). Como se observa, el amplio marco de necesidad en que se desenvuelven los inmigrantes, especialmente en su primera etapa, releva la importancia de las redes primarias.

En resumen, las redes sociales, las familiares y de amigos, establecen los vínculos primarios para la articulación del inmigrante al mundo laboral. Además de ser la institución básica de corresponsabilidad y solidaridad por las débiles protecciones sociales o estatales, contribuyen a situar al inmigrante en la estructura social, de tal forma que son también otro determinante explicativo de la situación laboral de la población inmigrante.

\section{Condiciones de trabajo de la población inmigrante}

En este tercer gran apartado, nos interesa profundizar en las condiciones de trabajo de la población inmigrante y en el grado de satisfacción de este colectivo con respecto a éstas. Para la mayor parte de los inmigrantes la situación actual representa solamente un episodio en su trayectoria laboral, aunque con frecuencia un episodio que ha supuesto romper bien con sus trayectorias laborales previas, ligadas a un oficio o profesión, o 
simplemente adentrarse en trabajos nunca realizados en sus países de origen, caso el servicio doméstico o la construcción. Al respecto un padre de una familia latinoamericana afirmaba:

"Desafortunadamente muchos venimos a desempeñar labores que no hacíamos en nuestro país, aquí te toca agachar mucho la cabeza, muchos profesionales trabajamos en la construcción, en trabajos que allí no haríamos".

Y su esposa continuaba:

"A mí me ha tocado sufrir muchas humillaciones. La persona con la que trabajaba yo antes, me trataba muy mal, ella creía que nosotros, en nuestro país, vivíamos en la calle, que no teníamos nada, que no sabíamos nada".

El hecho de abandonar su país por situaciones ajenas a su "voluntad" -ausencia de opciones- supone en el inmigrante una "voluntad domesticada". La mayoría de ellos sabe a qué viene, y muestra disposición a someterse con la esperanza de tener compensaciones futuras, más aún una parte acepta el marco de desigualdad de oportunidades entre sí mismo y el nativo como algo "natural". Una inmigrante latinoamericana comentaba:

“... Saber que estás en otro país y saberse comportar, porque si no... Debes saberte comportar, debes bajar la cabeza y portarse bien, ser muy correcto, nada de dejarse llevar por el temperamento, si es de temperamento fuerte ¡bájelo! Si le va a decir algo que no le gusta ¡bájelo! Eso es importante”.

Su escaso poder social de negociación, ligado a su situación irregular -especialmente en la primera etapa- les lleva a aceptar condiciones de trabajo rechazadas por buena parte de la población nativa. Trabajarán en donde "haya curro", con o sin contrato laboral, las horas que pueda - "cuantas más horas mejor"- y harán esfuerzos por subordinarse a la situación presente en espera de condiciones futuras mejores. En una primera etapa vivirán permanentemente en dos mundos, en el presente y en el pasado que se presentaliza y se vuelve futuro permanentemente; compararán su situación presente con las vivencias y oportunidades de su país de origen, situación que posiblemente les llevará a valorar la situación presente, además de considerarla como algo transitoria.

Según la encuesta el $62 \%$ de los hombres y el $57 \%$ de las mujeres señala sentirse satisfecho en su puesto de trabajo; mientras el $26 \%$ y el $32 \%$ respectivamente afirman 
sentirse poco satisfechos. En general se observa en las mujeres un menor grado de satisfacción en su trabajo. Sorprende el alto grado de satisfacción en el trabajo de la población inmigrante pues si consideramos algunos indicadores como: salarios, horas, funciones, estabilidad, promoción, formación, entre otros, éstos señalan las precarias condiciones de trabajo que, en términos generales, este colectivo se encuentra.

- Nivel de satisfacción salarial: En torno al 50\% de la población inmigrante ocupada, con o sin papeles, tiene un nivel de ingresos igual o inferior a los 600 euros mensuales $\underline{6}$, no obstante, el $56 \%$ de los hombres y el $45 \%$ de las mujeres afirman sentirse satisfechos con el salario. Es de recordar que la media salarial de las mujeres se sitúa en 425 euros mes y ello puede explicar que el $48 \%$ de las mismas estén nada o poco satisfechas con el salario.

- Nivel de satisfacción con las horas de trabajo: La media general en la primera experiencia laboral de los trabajadores inmigrantes en España se sitúa en 9,1 horas de trabajo/día y la del último o actual en 8,5. Continúan presentándose diferencias por género; la media de los hombres es de 9,1 y la de las mujeres de 7,7. Es de aclarar que la desviación típica es mayor en estas últimas, especialmente en el grupo de los sin contrato $(3,43$ frente a 2,79$)$. Las mujeres suelen contar con jornadas muy cortas (dos o tres horas) o trabajan hasta 16 horas/día, especialmente aquellas que están como internas en el servicio doméstico (Tabla 10).

Tabla 10

Horas de trabajo en la primera actual o última experiencia laboral según género

\begin{tabular}{lcccccccccc}
\hline \multirow{2}{*}{$\begin{array}{c}\text { Horas } \\
\text { Trabajadas }\end{array}$} & \multicolumn{3}{c}{ Primera ocupación } & \multicolumn{4}{c}{ Actual o última ocupación } \\
\cline { 2 - 10 } & \multicolumn{2}{c}{ Mujeres } & Hombres & & Mujeres & Hombres & \\
\cline { 2 - 10 } & $\%$ fila & $\%$ col. & $\%$ fila & $\%$ col. & Total & $\%$ fila & $\%$ col. & $\%$ fila & $\%$ col. & Total \\
Menos 8 hrs. & $80 \%$ & $29 \%$ & $20 \%$ & $6 \%$ & $16 \%$ & $86 \%$ & $38 \%$ & $14 \%$ & $5 \%$ & $20 \%$ \\
8 horas & $37 \%$ & $27 \%$ & $63 \%$ & $35 \%$ & $32 \%$ & $37 \%$ & $33 \%$ & $63 \%$ & $44 \%$ & $39 \%$ \\
Más 8 hrs. & $37 \%$ & $44 \%$ & $63 \%$ & $59 \%$ & $52 \%$ & $31 \%$ & $29 \%$ & $68 \%$ & $51 \%$ & $41 \%$ \\
\hline
\end{tabular}

Fuente: Encuesta 2002. Elaboración propia G540.

El nivel de satisfacción respecto a las horas de trabajo se sitúa en los hombres en un $67 \%$ frente al $56 \%$ de las mujeres. Cabe destacar que existe un núcleo bastante representativo que se encuentra en los apartados de poco y nada satisfecho, en el caso de los hombres estamos hablando de un $27 \%$ y en el de las mujeres de un $34 \%$. La insatisfacción puede radicar en que trabajan muy pocas horas o demasiadas. 
- Nivel de satisfacción con la estabilidad laboral: La primera experiencia laboral del 95\% del total del colectivo la realizan "sin contrato". Si se compara el primer contrato con el actual o último se observa que los contratos temporales crecen 15 veces más y los indefinidos 22 veces, mientras la categoría "sin contrato" decrece más de la mitad.

Pero si analizamos el grupo de no regularizados prácticamente el cien por ciento de los encuestados continúan trabajando sin contrato, mientras en el grupo regularizado sólo lo hace el $17 \%$ del total (el $28 \%$ de las mujeres y el $9 \%$ de los hombres). La gran mayoría tiene contratos temporales, en torno al $50 \%$ (mientras la tasa de temporalidad de la población española es de $35,7 \%$ ). Sólo el $33 \%$ de los hombres y el $14 \%$ de las mujeres inmigrantes cuentan con contrato indefinido en el momento de ser encuestados. Una minoría trabaja por cuenta propia (9\%) (Tabla 11).

Tabla 11

Actual o último contrato por género de los trabajadores regularizados

\begin{tabular}{lcccccccc}
\hline & \multicolumn{3}{c}{ Hombre } & \multicolumn{3}{c}{ Mujer } & \multicolumn{3}{c}{ Total } \\
\cline { 2 - 9 } & $N^{0}$ & $\%$ fila & $\%$ col. & $N^{0}$ & $\%$ fila & $\%$ col. & $N^{2}$ & $\%$ col. \\
\hline Temporal & 85 & $62,0 \%$ & $50,6 \%$ & 52 & $38,0 \%$ & $47,7 \%$ & 137 & $49,5 \%$ \\
Indefinido & 55 & $78,6 \%$ & $32,7 \%$ & 15 & $21,4 \%$ & $13,8 \%$ & 70 & $25,3 \%$ \\
Cuenta propia & 13 & $54,2 \%$ & $7,7 \%$ & 11 & $45,8 \%$ & $10,1 \%$ & 24 & $8,7 \%$ \\
Sin contrato & 15 & $32,6 \%$ & $8,9 \%$ & 31 & $67,4 \%$ & $28,4 \%$ & 46 & $16,6 \%$ \\
Total & 168 & $60,6 \%$ & $100,0 \%$ & 109 & $39,4 \%$ & $100,0 \%$ & 277 & $100,0 \%$ \\
\hline
\end{tabular}

Fuente: Encuesta 2002, elaboración propia G540.

En cuanto a la duración del actual o último contrato, el $11 \%$ de los inmigrantes tenían un contrato de un mes de duración, el $27 \%$ inferior a tres meses, el $48 \%$ menor a seis meses, y el $72 \%$ inferior a un año. Respecto a los motivos de finalización del trabajo, el $32 \%$ del total de inmigrantes termina su primer contrato laboral por "fin de obra", esta situación es más vivida por los hombres: el $81 \%$ frente al $19 \%$ de las mujeres. Situación que puede ser explicada por las características del sector en que están ocupados la mayoría de ellos (construcción). Sólo el $6 \%$ del total de los encuestados había sido despedido en su primer trabajo y el $11 \%$ en su último.

Intentando medir las estrategias individuales de los inmigrantes se preguntó por el abandono del puesto de trabajo motivado por la "búsqueda de un mejor empleo" y el "voluntario forzado", interpretado este último como la decisión de abandonar el trabajo por las malas condiciones del mismo. El 62\% del total de la población lo abandonó por los anteriores motivos, dentro de la cual el $81 \%$ eran mujeres y el $48 \%$ eran hombres. El ítem estabilidad presenta puntuaciones de satisfacción más bajas en comparación con las 
reflejadas en la valoración sobre los salarios y las horas de trabajo. El $48 \%$ de los hombres dice sentirse nada o poco satisfecho con las condiciones de estabilidad laboral, porcentaje muy similar al de las mujeres.

- Nivel de satisfacción con las funciones desempeñadas: Sorprende el alto nivel de satisfacción en las funciones realizadas manifestado por los inmigrantes, cuando la gran mayoría de ellos se encuentran realizando trabajos no cualificados y poco acordes con su formación. Vale recordar que el $69 \%$ del total de la población posee alguna cualificación (oficios o estudios universitarios) de la cual el $67 \%$ de la misma desempeña trabajos no cualificados, especialmente las mujeres cuyo porcentaje asciende al 91\%. El 77\% de los hombres y el $69 \%$ de las mujeres dicen sentirse satisfechos o muy satisfechos con las funciones realizadas, independientemente del nivel de cualificación.

¿El nivel de satisfacción en el trabajo depende de las cualificaciones de los inmigrantes? ¿Es posible esperar que aquellos con mayor potencial ubicados en labores no cualificadas tengan mayor nivel de insatisfacción?

Si se analizan variables muy puntuales como son: salarios, horas de trabajo, estabilidad laboral, funciones realizadas, entre otras, sí se observan diferencias en cuanto al nivel de satisfacción en los diversos grupos por nivel de cualificación. Primero, en general se observa un mayor nivel de satisfacción del género masculino en todos los ítem (salarios, horas trabajadas, estabilidad laboral y funciones realizadas). Segundo, no se presentan mayores diferencias en cuanto a la valoración de la satisfacción en los diferentes ítem por nivel de cualificación, especialmente en el caso de los hombres, en el grupo de mujeres se observa mayor heterogeneidad en las respuestas. Tercero, los hombres tienden a valorar más positivamente que las mujeres sus condiciones de trabajo, acorde esto con su relativa mejor situación en el mercado laboral respecto a las mujeres. Es así como las funciones realizadas se ubican en el primer lugar de valoración positiva, seguida de las horas trabajadas, del salario y la peor valorada es la estabilidad laboral. Mientras las mujeres señalan igual orden pero en una escala menor.

Pero si se analiza la pregunta “¿Cómo se siente en el puesto de trabajo? (nada satisfecho, poco satisfecho, satisfecho y muy satisfecho)", en los datos que se desprenden de la muestra analizada no se observan diferencias significativas entre las personas de acuerdo a su cualificación, ocupen o no trabajos cualificados. El $70 \%$ de los ocupados en trabajos no cualificados afirmaron sentirse satisfechos o muy satisfechos. I gual porcentaje arrojan los ocupados en trabajos cualificados (Gráfico 7). 


\section{Gráfico 7}

Cualificados por nivel de

satisfacción en su actual

o último trabajo

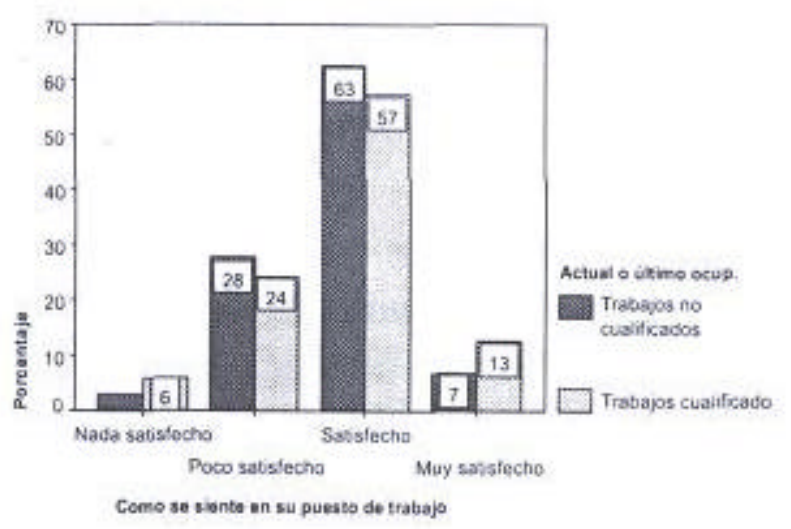

Fuente: Encuesta 2002. Elaboración propia G540.

Tampoco se observan diferencias significativas en el grupo de trabajadores no cualificados, el $66 \%$ ubicado en trabajos no cualificados dice sentirse satisfecho o muy satisfecho, mientras dicha afirmación es reiterada por el $72 \%$ de los que realizan trabajos cualificados (Gráfico 8).

\section{Gráfico 8 \\ No cualificados por nivel de satisfacción en su actual \\ o último trabajo}

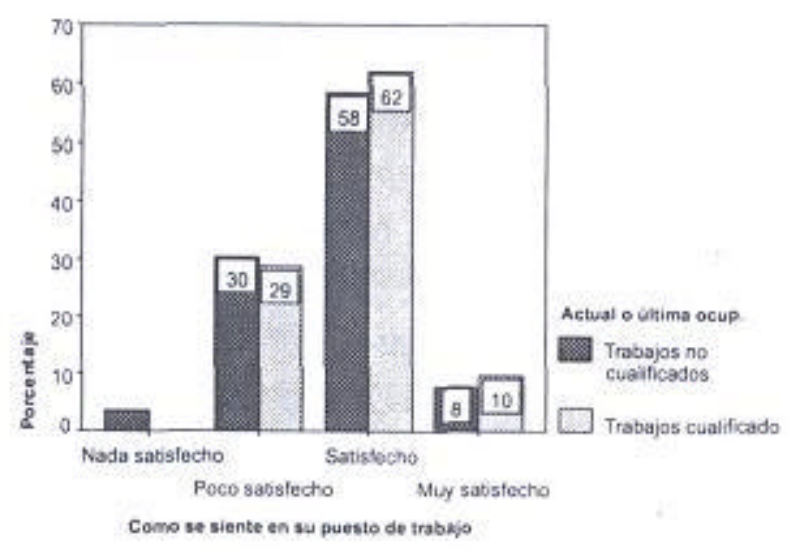

Fuente: Encuesta 2002. Elaboración propia G540.

Si consideramos la variable género tampoco se observan diferencias significativas entre los grupos de cualificados y no cualificados. Es decir, que independientemente de la cualificación e incluso del tipo de trabajo realizado (cualificado o no) los niveles de satisfacción se mueven en parámetros similares, en torno al $70 \%$ de los encuestados 
señalan sentirse satisfechos o muy satisfechos.

¿Cómo se entiende la paradoja de que los inmigrantes encuestados, ante preguntas específicas en cuanto a condiciones de trabajo (salarios, horas de trabajo, funciones realizadas, estabilidad laboral, entre otras), presenten un grado de satisfacción aceptable, y más elevado del que se pudiera pensar a priori, dadas la condiciones precarias de trabajo? Podemos señalar algunas hipótesis explicativas de dicho fenómeno, con la salvedad que debe ser fruto de un estudio más en profundidad.

Primero, el tiempo podría ser una variable explicativa del grado de satisfacción de la población inmigrante con respecto a su trabajo. El tiempo supone, entre otras, la regularización de algunos colectivos, el conocimiento del idioma, de la normativa que rige en el mercado laboral, la posibilidad de reconocimiento de sus cualificaciones, la construcción de nuevas redes sociales, además de su "adaptación" a la sociedad de acogida. Es así que habría que esperar que el contingente más "satisfecho" sea el que lleva más años viviendo en España. Más aún su satisfacción puede estar ligada al conocimiento del mercado laboral y de sus limitadas oportunidades, situación que le lleva no sólo al reconocimiento del orden social existente sino a su aceptación. Además, posiblemente con el tiempo su marco de referencia no sea su país de origen sino la cantidad de población autóctona que se encuentra en similar situación, debido a la flexibilización de los mercados de trabajo.

Al considerar la variable tiempo en las encuestas, se observa que a su llegada el inmigrante tiene un grado importante de insatisfacción, la cual a partir de los seis meses empieza a descender. Es decir, parece existir un grado de "adaptación" del inmigrante con las condiciones de trabajo que oferta el mercado laboral. Lo anterior es claro para el caso del grado de insatisfacción respecto a los salarios y las funciones: el 58\% de total de los inmigrantes recién llegados a España señalan sentirse nada o poco satisfecho con los salarios y el $41 \%$ con las funciones realizadas. Este porcentaje se estabiliza alrededor del $40 \%$ y $24 \%$ respectivamente, en aquellos que llevan una estancia mayor.

Mientras, el nivel de insatisfacción respecto a la estabilidad laboral presenta un descenso más prolongado en el tiempo y menos acusado que los anteriores. El $69 \%$ de los inmigrantes con menos de seis meses en España señala sentirse nada o poco satisfecho con la estabilidad laboral, el transcurso del tiempo se observa una tendencia a disminuir el nivel de insatisfacción situándose en el $41 \%$ a partir de los dos años.

El tiempo también está ligado a la posibilidad de regularización y con ello a la ampliación 
de oportunidades en el mercado de trabajo y de estrategias de la población inmigrante. El $78 \%$ de los regularizados manifestaron sentirse satisfechos con las condiciones generales de su actual o última ocupación; mientras el $65 \%$ de los no regularizados afirmaron sentirse nada satisfechos. Por lo que podemos deducir que el hecho de tener o no regularizada la situación legal, incide de manera significativa en las condiciones de trabajo de los inmigrantes y en el grado de satisfacción frente a las mismas.

Segundo, algunos estudios señalan que los inmigrantes permanentemente comparan su situación presente no con el colectivo autóctono sino con su vivencias y oportunidades que considera podría tener en su país de origen $\underline{7}$. Es evidente que en la mayoría de los casos el hecho de inmigrar no es un "acto voluntario", es la ausencia de elecciones, de oportunidades, lo que lleva a abandonar el país de origen. La encuesta señala que el 63\% abandonó su país por motivos económicos y el $12 \%$ por motivos políticos y económicos.

Al preguntarle a los inmigrantes "respecto a su lugar de origen, considera su nivel de vida actual: peor, igual, mejor, mucho mejor", el $64 \%$ de los encuestados responde que se encuentra mejor con su nivel de vida actual y el 10\% afirma "estar mucho mejor". Podría pensarse que cuando se les preguntó a los inmigrantes sobre su satisfacción, bien en el trabajo en general o sobre determinadas condiciones, su marco de referencia no son las condiciones generales de la población española sino la que ellos tendrían en el evento de estar en su país de origen, de ahí su consideración positiva frente al trabajo en general. Y como ya se señaló, en aquellos que llevan una estancia prolongada en España, su grupo de referencia posiblemente sí sea una parte de la población nativa que como ellos se encuentra en similares condiciones de trabajo. Más aún, para la gran mayoría de inmigrantes el arribar a un país como España de partida le supone una ganancia, entre otras cosas por su Estado de Bienestar, el cual se cristaliza en unas condiciones generales de vida y de convivencia valoradas por la población inmigrante. De ahí que a pesar de la estructura de desigualdad de oportunidades en que se encuentran, en la mayoría de los casos ven como positivo el hecho de inmigrar, a pesar de las nostalgias, sacrificios y/o humillaciones que muchos de ellos han tenido que afrontar.

Por último, sin plantear un determinismo social, pues los actores elaboran estrategias que se cristalizan en diferencias situacionales entre ellos mismos, las instituciones construidas en los ámbitos político, social, cultural y económico determinan la situación laboral de la población inmigrante al contribuir a la configuración de una estructura de desigualdad de oportunidades. Instituciones tales como el marco legal y la estructuración del mercado de trabajo, sumadas a las redes sociales a las cuales se articulan los inmigrantes, determinan las probabilidades de integración al mercado de trabajo de este 
colectivo, base fundamental para su integración social. Sin la integración laboral, estas minorías no podrán participar de manera activa en la vida económica, social, ávica y cultural del país de acogida, y no se convertirán en agentes sociales creativos, capaces de aportar lo mismo que de recibir.

En fin, la cuestión fundamental es que los procesos de exclusión son una construcción social, por ello el reto sigue siendo encontrar un modelo de sociedad en la que se reconozca el pluralismo y se concilie el principio de ciudadanía y de igualdad civil y política, por una parte, y el derecho a la diferencia por otra.

\section{Conclusiones}

Podemos concluir lo siguiente: Primero, el colectivo estudiado se caracteriza por pertenecer a la primera generación de inmigrantes y por contar con un nivel de cualificación importante en oficios profesionales y estudios universitarios, que difícilmente le es reconocido en el mercado de laboral.

Segundo, en su primer trabajo, los inmigrantes se ubican indiscriminadamente, cualificados o no cualificados, hombres o mujeres, en mercados de trabajo secundarios, caracterizados por su poca cualificación, esfuerzo físico importante, baja remuneración, poco reconocimiento social y sin relación contractual formal y estable. Esto supone para algunos de ellos (cualificados y universitarios) "truncar sus carreras laborales y/o profesionales".

Tercero, a pesar de las condiciones de partida bastante homogéneas entre los diferentes colectivos de inmigrantes, en las trayectorias no solamente se manifiestan "procesos estructurales" de la "asignación a posiciones sociales", sino que éstas son resultado también de decisiones y de estrategias de los actores - pero siempre en un espacio social limitado y definido no solamente por las oportunidades y la dinámica del mercado de trabajo sino también por las instituciones y normas sociales que delimitan, restringen y canalizan las opciones - .

Por ello, aunque de partida casi todos los inmigrantes cuentan con similar situación laboral, en la medida que pasa el tiempo y logran regularizar su situación legal, las trayectorias de los hombres con oficios profesionales y de las mujeres toman caminos muy diferentes, a la vez que persisten las diferencias entre los regularizados y los no regularizados. Las mujeres y los hombres no cualificados y no regularizados tienden a permanecer en los segmentos más precarios de mercados secundario, poco regularizado. 
Sin mayores barreras institucionales entran y salen en estos mercados abiertos, con pocas oportunidades para arraigarse, pues su situación actual es considerada como transitoria.

Por el contrario, los inmigrantes hombres con oficios profesionales tienen mayores probabilidades de movilidad laboral e incluso social. Ya regularizados, pueden entrar a competir con los nativos y ocupar puestos de trabajo que el mercado laboral demanda, situación que abre caminos a un grupo -aunque bastante reducido- para la realización de carreras laborales en segmentos de mercado más regularizados.

Cuarto, uno de los puntos de inflexión de las trayectorias laborales es el momento de la regularización. Esto supone al inmigrante abandonar su condición de "inexistencia legal", reconocerse como portador de derechos sociales -aunque limitados- que le proveen de una mayor libertad para adelantar estrategias no sólo en el ámbito laboral sino social, además, le brinda la posibilidad de dejar de transitar por la economía sumergida.

Quinto, los diferentes caminos que toman las trayectorias laborales de los diversos grupos de inmigrantes tienen expresión en las remuneraciones, es así como las mujeres y los inmigrantes sin papeles se ubican en la escala salarial más baja, mientras aquellos que presentan trayectorias ligadas a oficios profesionales demandados por el mercado presentan mayores ingresos respecto a dichos grupos.

En resumen, podemos concluir que las hipótesis de partida tienen validez explicativa, es decir, en torno a las diferencias se construyen desigualdades las cuales se cristalizan en una estructura de desigualdad de oportunidades, que reviste al inmigrante de déficit situacional. Bajo estas circunstancias, el marco institucional-legal, la condición de género, la cualificación y las redes sociales, son factores explicativos de la situación laboral de la población inmigrante, razón por la cual la sociedad de acogida debería adelantar políticas orientadas a reducir la desigualdad de oportunidades de este colectivo.

\section{Notas}

* Este artículo es el resultado de un estudio realizado para el Ayuntamiento de Alcalá de Henares (España) con el apoyo de la Cruz Roja, que indagaba sobre la situación socio laboral de la población inmigrante de dicha ciudad. Además de la autora participaron en las diversas fases del estudio (formulación del problema, realización de encuestas y análisis) Laura Bautista, Carmen Blanco, Marta Martínez, Soledad Rincón, Margarita Sánchez y Luis María Asenjo. Agradezco en especial a Carmen Blanco y a Luis Asenjo por su participación en la tabulación y análisis de la problemática laboral de este colectivo, los cuales han sido utilizado en el presente artículo, y a Enrique Seco por los 
comentarios al texto.

1. Se entenderá como formación profesional aquella que aporta cualificaciones de tipo medio, técnica o de oficios, bien en áreas administrativas, industriales, artesanales o de servicios.

2. Como señala Solano: “El servicio doméstico es un ámbito laboral escasamente regulado: no se exige contratación por escrito ni formalizar ésta con el INEM, basta que se haya acordado verbalmente; está excluido del R égimen General de la Seguridad Social, tiene un régimen específico, y sólo se exige la afiliación a la Seguridad Social a partir de un determinado número de horas de trabajo; es difícilmente controlable a través de los medios regulares y públicos de inspección. Además, quienes trabajan en el mismo no tienen derecho a acceder a la prestación por desempleo, desarrollan extensas jornadas (la jornada máxima laboral es de 40 horas) y perciben bajas retribuciones económicas (en el año 2000 su cómputo mensual estaba fijado en 70.680 pesetas [424 euros] al mes, y, si el servio se prestaba por horas, en 549 pesetas [3,30 euros] la hora; se admite la posibilidad de descontar hasta un máximo del $45 \%$ del salario por manutención, alojamiento y otra compensaciones). La falta de regulación legal es aún mayor en le cuidado de ancianos y enfermos, y no digamos en la prostitución" (Solano, 2003:5).

3. Al igual que en caso de las mujeres con la prostitución, el estudio no registra tampoco el trabajo agrícola, debido a que Alcalá de Henares hace parte del cinturón industrial madrileño. Situación esta no representativa para el caso de la población masculina inmigrante en España que suele ocuparse en labores agrícolas (14,2\% frente al 7,9\% de españoles) (Martín, 2003: 13).

4. En este caso la palabra "contingente" tiene una acepción jurídica, referida al cupo de ofertas de trabajo que anualmente el gobierno español determina para que sea cubierta con mano de obra extranjera. En el contingente se determinan las características de las ofertas: sector de actividad (fundamentalmente agricultura, construcción, hostelería, comercio, transporte y servicio doméstico), ocupación, provincia, tipo de permiso (renovable o de temporada). En el año 2002 se fijó un contingente inicial de 10.884 permisos de carácter renovable y 21.195 de temporada. En el 2003 se estableció una previsión inicial de 10.575 permisos renovables y 23.582 de temporada (Martín, 2003: 26).

5. Es importante destacar que al no considerar el colectivo de mujeres inmigrantes trabajando en la prostitución la media salarial de este colectivo baja, pues algunos estudios señalan que esta ocupación suele ser bastante mejor remunerada que las vinculadas al servicio doméstico u hostelería (Solano, 2003).

6. Es necesario aclarar que el alquiler de un apartamento o piso en Alcalá de Henares puede estar alrededor de los 500 euros y el de un cuarto o habitación 210 euros, sin incluir el pago de servicios.

7. “Los niveles de protección social vía prestaciones públicas, las redes de cobertura sociales y familiares, las expectativas y estilos de vida y de trabajo, hacen "inapropiados" para muchos parados autóctonos ciertos empleos. 
Estos son ocupados por los extranjeros, quienes cuentan con menor capacidad para defender su posición y, en principio, cifran sus expectativas en términos (económicos y sociales) de la sociedad de origen más que de la de destino" (Colectivo IOE, 2000: 110).

\section{Referencias Bibliográficas}

1. Ayuntamiento de Alcalá de Henares (2003), Padrón Municipal de 2002 y 2003, Alcalá de Henares.

2. Castel, Robert (1995), Las metamorfosis de la cuestión social, una crónica del salariado. Paidos, Estado y Sociedad, México.

3. Colectivo IOÉ (2003), Inmigración, escuela y mercado de trabajo, una radiografía actualizada. Fundación “La Caixa”, Madrid.

4. Dombois, Rainer (1997), “Relaciones industriales y condiciones laborales", en: Weiss, Anita (editor), Modernización industrial: empresas y trabajadores. Universidad Nacional de Colombia, Departamento de Sociología, Bogotá.

5. Duran, M., Serra, I., y Torada, R. (2001), Mujer y Trabajo, problemática actual. Germania Serveis Gráfics, S.L., Valencia.

6. Instituto Nacional de Estadística, INE (2003), www.ine.es: INE BASE, España.

7. López, Carmen Marina (2002), Las relaciones laborales en Colombia, vista bajo la teoría de las Opciones Estratégicas de los Actores. Universidad Complutense de Madrid, en proceso de edición en CD.

8. Martín, Carlos (2003), “Trabajadores extranjeros y acción sindical”. Ponencia sin publicar, CCOO, Madrid.

9. Massey, D., Alarcón, R., Durand, J. y Gonzalez, M. (1987), Return to Aztlan: the social process of international migration from western México, Berkeley: University of California Press.

10. Merino, M. (2002), Historia de los inmigrantes peruanos en España, dinámicas de exclusión e inclusión en una Europa globalizada. Consejo Superior de Investigaciones Científicas, Madrid. 
11. Moreno, José (2003), “Inmigración en España: entre la demagogia y la incompetencia", ponencia sin publicar, CCOO, Madrid.

12. Prieto, Carlos (1994), Los trabajadores y sus condiciones de trabajo. Ediciones Hoac, Madrid.

13. Prieto, Carlos (2001), “Trabajo y globalización económica”, en: Globalización, trabajo y movimiento sindical, Jornadas, DG VIII de la Comisión Europea, CCOO y Fundación Paz y Solidaridad, España.

14. Solano, José Luis (2003), Prostitución, tráfico e inmigración de mujeres, Ayuntamiento de Córdoba, Área de Mujer, Juventud y Empleo. Editorial Comares, Granada.

15. Oso, L., (1998), La migración hacia espala de mujeres jefas de hogar. Instituto de la Mujer, Madrid. 